\title{
Uptake Rates of Novel Therapies and Survival Among Privately Insured Versus Publicly Insured Patients With Colorectal Cancer in Germany
}

\author{
Lina Jansen, MSc, PhD ${ }^{1, \star}$; Daniel Boakye, $\mathrm{PhD}, \mathrm{MPH}^{1, \star}$; Elizabeth Alwers, MSc, MD${ }^{1}$; Prudence R. Carr, MSc, $\mathrm{PhD}^{1}$; \\ Christoph Reissfelder, MD²; Martin Schneider, MD³ Uwe M. Martens, MD4; Jenny Chang-Claude, MSc, PhD5,6; \\ Michael Hoffmeister, MSc, $\mathrm{PhD}^{1}$; and Hermann Brenner, MD, MPH ${ }^{1,7,8}$
}

\section{ABSTRACT}

Background: In the era of personalized medicine, cancer care is subject to major changes and innovations. It is unclear, however, to what extent implementation of such innovations and their impact on patient outcomes differ by health insurance type. This study compared provision of treatment and survival outcomes among patients with colorectal cancer (CRC) who had statutory health insurance $(\mathrm{SHI})$ versus private health insurance (PHI) in Germany. Methods: We analyzed patterns of CRC treatment (surgery, chemotherapy/radiotherapy, and targeted therapy) and survival in a large cohort of patients who were diagnosed with CRC in 2003 through 2014 and were observed for an average of 6 years. Associations of type of health insurance with treatment administration and with overall, CRC-specific, and recurrence-free survival were investigated using multivariable logistic and Cox proportional hazards models, respectively. Results: Of 3,977 patients with CRC, 427 (11\%) had PHI. Although type of health insurance was not associated with treatment administration in patients with stage I-III disease, those with stage IV disease with $\mathrm{PHI}$ more often received targeted therapy ( $65 \%$ vs $40 \%$; odds ratio, $2.43 ; 95 \% \mathrm{Cl}, 1.20-4.91)$, with differences decreasing over time because of catch-up of uptake rates in patients with SHI. Median overall survival was longer in patients with $\mathrm{PHI}$ than in those with $\mathrm{SHI}$ (137.0 vs 114.9 months; $P=.010$ ), but survival advantages were explained to a large extent by differences in sociodemographic factors. In patients with stage IV disease, survival advantages of PHI were nonsignificant and were restricted to the early years after diagnosis. Conclusions: We observed major differences in uptake of targeted therapy between patients with $\mathrm{PHI}$ and those with $\mathrm{SHI}$ but no differences in patient survival after adjusting for relevant sociodemographic, clinical, and tumor characteristics. Further studies are needed on factors associated with the uptake of therapeutic innovations and their impact on patient survival by health insurance type.

J Natl Compr Canc Netw 2021;19(4):411-420 doi: $10.6004 /$ jnccn.2020.7636

See JNCCN.org for supplemental online content.

\section{Background}

Colorectal cancer (CRC) is the second major cause of cancer-related deaths, accounting for approximately 862,000 deaths per year globally. ${ }^{1}$ Along with advancements in early detection and therapy, CRC prognosis has steadily improved in many countries in recent decades, ${ }^{2}$ with 5-year relative survival reaching approximately $65 \%$ in several countries, including the United States ${ }^{3}$ and Germany. ${ }^{4}$

Surgical removal of the primary tumor has been complemented by major therapeutic innovations within the past decades, such as neoadjuvant chemotherapy/radiotherapy (forstage II-III rectal cancer), adjuvant chemotherapy/ radiotherapy (often for stage III colon cancer or stage II-III rectal cancer), and targeted therapy (eg, bevacizumab for stage IV CRC). Some of these innovations (eg, targeted therapy) are associated with major increases in costs, ${ }^{5}$ and their implementation may vary according to health insurance coverage. Meta-analyses of clinical trials have demonstrated that the addition of bevacizumab to standard first-line treatment of metastatic CRC improves progression-free survival by between $31 \%$ and $56 \%(P<.001),{ }^{6,7}$ Thus, differences in uptake of these therapeutic innovations by insurance status might lead to variations in survival within patient groups eligible for such treatments.

\footnotetext{
${ }^{1}$ Division of Clinical Epidemiology and Aging Research, German Cancer Research Center (DKFZ), Heidelberg; ${ }^{2}$ Department of Surgery, University Hospital Mannheim, Medical Faculty Mannheim, Heidelberg University, Mannheim; ${ }^{3}$ Clinic for General, Visceral, and Transplantation Surgery, Heidelberg University Hospital, Heidelberg; ${ }^{4}$ SLK-Clinics, Cancer Center Heilbronn-Franken, Heilbronn; ${ }^{5}$ Unit of Genetic Epidemiology, Division of Cancer Epidemiology, German Cancer Research Center (DKFZ), Heidelberg; ${ }^{6}$ Cancer Epidemiology Group, University Cancer Center Hamburg (UCCH), University Medical Center Hamburg-Eppendorf (UKE), Hamburg; and ${ }^{7}$ Division of Preventive Oncology, and ${ }^{8}$ German Cancer Consortium, German Cancer Research Center (DKFZ), Heidelberg, Germany.
}

*These authors contributed equally to this study. 
In Germany, health insurance is compulsory and most people are covered by statutory health insurance (SHI; $\sim 89 \%$ ), whereas a minority of the population $(\sim 11 \%)$ receive their primary coverage through private health insurance (PHI) ${ }^{8,9}$ Eligibility for PHI is mostly defined by income level, which must exceed defined thresholds. PHI differs from SHI in terms of benefits and incentives against overuse of health services and remuneration of care providers. ${ }^{10}$ It is unclear, however, if and to what extent such differences impact treatment and outcomes of patients with CRC.

We investigated the associations of type of health insurance with utilization of treatments and survival in a cohort of patients with CRC recruited in a populationbased study in Germany, paying particular attention to uptake of targeted therapy among patients with stage IV disease.

\section{Methods}

\section{Study Population}

This patient cohort analysis is based on data from the DACHS (Darmkrebs: Chancen der Verhütung durch Screening) study. The DACHS study is an ongoing population-based case-control study on CRC with additional patient follow-up, which has been conducted in southwest Germany since 2003. It was primarily designed to assess the potential of endoscopic screening for the prevention of CRC. Patients with a histologically confirmed, first-time diagnosis of CRC (ICD-10 codes C18-C20); aged $\geq 30$ years; and physically able to participate in a 1-hour interview are eligible. All 22 hospitals in the study area offering first-line treatment to patients with CRC are involved in recruitment. Approximately $50 \%$ of all eligible patients in the study area have been recruited. Incomplete recruitment is mainly the result of work overload of the clinicians involved in recruiting patients in the study settings. Further details of the DACHS study have been previously reported. ${ }^{11,12}$ The DACHS study was approved by the ethics committees of the University ofHeidelberg and the state medical boards of Baden-Wuerttemberg and Rhineland-Palatinate. Written informed consent was obtained from each participant. The current analysis includes patients diagnosed in 2003 through 2014.

\section{Data Collection}

Shortly after CRC diagnosis, patients participated in an interview with trained interviewers, who collected information on sociodemographic, medical, and lifestyle history using a standardized questionnaire. In addition, discharge letters and pathologic reports were collected, and detailed information on tumor and medical characteristics were extracted. Information on type of insurance coverage at the time of CRC diagnosis was obtained from the treating hospitals.

Vital status and cause of death were ascertained from population registries and public health authorities approximately 3,5 , and 10 years after diagnosis. Approximately 3 years after diagnosis, a questionnaire was sent to the treating physicians, and medical reports were collected to obtain information on CRC treatment and recurrence. After 5 and 10 years, questionnaires were sent to the patients to obtain, among other things, information on recurrence status. In cases of reported CRC recurrence, the treating physician was contacted for validation and to obtain further details. For patients who died during follow-up or were lost to follow-up, recurrence history was obtained from the last attending physician.

\section{Inclusion Criteria}

Patients with CRC diagnosed in 2003 through 2014 who were followed up for 3 (2011-2014), 5 (2007-2010), or 10 years (2003-2006) were included. Patients with no information on insurance and vital status or who did not participate in the 3-year follow-up were excluded (Figure 1).

\section{Definition of Variables}

Demographic characteristics (sex and age at diagnosis), social characteristics (education level and living with a partner), lifestyle score, clinical characteristics (Charlson comorbidity score and regular use of statins and nonsteroidal anti-inflammatory drugs [NSAIDs], including aspirin), tumor-related characteristics (year of diagnosis, cancer stage, and cancer site), and treatment characteristics (surgery type and first-line treatments

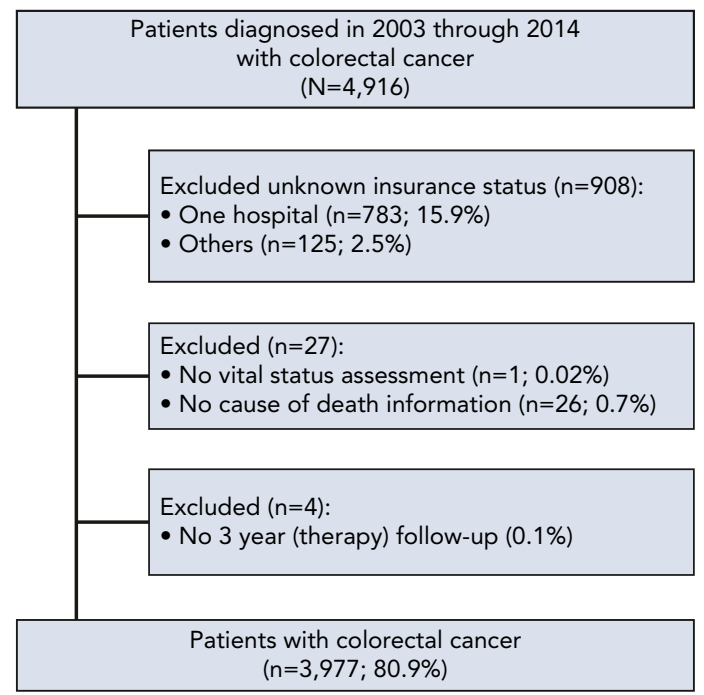

Figure 1. Flowchart showing selection of the study population. 
[neoadjuvant/adjuvant/palliative chemotherapy, radiotherapy, and targeted therapy]) were selected a priori for analyses.

A lifestyle score was used as a proxy for healthy lifestyle behavior before diagnosis. It was derived from 5 lifestyle factors (smoking, alcohol consumption, diet, physical activity, and body mass index), as described previously. ${ }^{13}$ The Charlson comorbidity index score ${ }^{14}$ (adapted by Deyo et $\mathrm{al}^{15}$ ) was derived from comorbidities that were diagnosed either before or at the time of CRC diagnosis, as described elsewhere. ${ }^{16}$ Cancer stage was categorized into 4 groups (I-IV). ${ }^{17}$

Follow-up started from CRC diagnosis. Endpoints for survival analyses were overall survival (OS; death from any cause), CRC-specific survival (CSS; death from CRC), and recurrence-free survival (RFS; recurrence of or death from CRC). Patients with stage IV disease were excluded from RFS analysis because of the low number of patients with RFS, especially in the small group of patients with PHI and stage IV disease.

\section{Statistical Analyses}

Distributions of demographic, social, lifestyle, clinical, tumor-related, and treatment-related characteristics according to insurance type were assessed. Before multivariable analyses, multiple imputation was conducted (supplemental eAppendix 1 and eTable 1 , available with this article at JNCCN.org). Multivariable logistic regression models were used to explore whether type of insurance was associated with treatment patterns (type of surgery, chemotherapy/radiotherapy, and targeted therapy). Because treatment depends on cancer site and stage, stratified analyses were conducted following treatment recommendations according to the German S3-guideline for CRC. ${ }^{18,19}$ All models were adjusted for demographic, social, lifestyle, clinical, and tumor-related factors.

Median follow-up time was computed using the Kaplan-Meier estimate of potential follow-up. ${ }^{20}$ Associations of insurance type with survival, overall and by tumor stage, were assessed univariately using KaplanMeier curves. Differences in survival were tested for statistical significance using the Wilcoxon test because they mostly occurred in the earlier years after diagnosis. Hazard ratios (HRs) and 95\% confidence intervals for the association of insurance type with survival were estimated using multivariable Cox proportional hazards regression at different censoring times (because they seemed to vary by follow-up time, even though there was no obvious violation in the proportional hazards assumption) and in different adjustment levels. The basic model included demographic characteristics. Adjustment was gradually extended by

\begin{tabular}{|c|c|c|c|}
\hline Treatment Patterns & $\begin{array}{c}\text { SHI } \\
\text { n (\%) }\end{array}$ & $\begin{array}{c}\text { PHI } \\
\text { n (\%) }\end{array}$ & OR $(95 \% \mathrm{Cl})^{\mathrm{a}}$ \\
\hline \multicolumn{4}{|c|}{ Stage I-IV CRC with surgery } \\
\hline \multicolumn{4}{|l|}{ Type of surgery } \\
\hline Open & $2,967(85.1)$ & $341(81.0)$ & Ref \\
\hline Laparoscopic & $518(14.9)$ & $80(19.0)$ & $1.17(0.87-1.57)$ \\
\hline \multicolumn{4}{|l|}{ Stage III colon cancer } \\
\hline \multicolumn{4}{|c|}{ Adjuvant chemotherapy } \\
\hline No & $158(24.6)$ & $18(22.8)$ & Ref \\
\hline Yes & $487(75.4)$ & $62(77.2)$ & $0.65(0.31-1.35)$ \\
\hline \multicolumn{4}{|c|}{ Stage III colon cancer, age $<70 \mathrm{y}$, adjuvant chemotherapy ${ }^{b}$} \\
\hline \multicolumn{4}{|c|}{ Oxaliplatin-based chemotherapy } \\
\hline No & 25 (12.3) & $5(13.5)$ & Ref \\
\hline Yes & $178(87.7)$ & $32(86.5)$ & $0.65(0.21-2.05)$ \\
\hline \multicolumn{4}{|c|}{ Stage II-III rectal cancer } \\
\hline \multicolumn{4}{|c|}{ Neoadjuvant radiotherapy } \\
\hline No & $380(55.6)$ & $42(51.1)$ & Ref \\
\hline Yes & $303(44.4)$ & $41(48.9)$ & $1.01(0.60-1.69)$ \\
\hline \multicolumn{4}{|l|}{ Stage IV CRC ${ }^{c}$} \\
\hline \multicolumn{4}{|l|}{ Targeted therapy } \\
\hline No & $245(60.1)$ & $18(34.7)$ & Ref \\
\hline Yes & $162(39.9)$ & $34(65.3)$ & $2.43(1.20-4.91)$ \\
\hline \multicolumn{4}{|l|}{ Stage IV CRC } \\
\hline \multicolumn{4}{|l|}{ Bevacizumab } \\
\hline No & $283(69.5)$ & $25(48.1)$ & Ref \\
\hline Yes & $124(30.5)$ & $27(51.9)$ & $2.46(1.26-4.79)$ \\
\hline
\end{tabular}

Bold indicates statistically significant results.

Abbreviations: CRC, colorectal cancer; OR, odds ratio; PHI, private health insurance; $\mathrm{SHI}$, statutory health insurance.

aOR from multivariable logistic regression with adjustment for sex, age at diagnosis, years of schooling, living with a partner, lifestyle score, Charlson comorbidity score, regular use of statins, regular use of nonsteroidal antiinflammatory drugs, year of diagnosis, cancer stage, and cancer site ( $r e f=\mathrm{SHI})$. bAnalysis was restricted to years of diagnosis $\geq 2005$, because oxaliplatin had not been approved for treatment of patients with stage III colon cancer before 2005.

cAnalysis was restricted to years of diagnosis $\geq 2005$, because no patient received targeted therapy before 2005 .

${ }^{\mathrm{d}}$ Analysis was restricted to years of diagnosis $\geq 2005$, because no patient received bevacizumab before 2005 (patients receiving targeted therapy other than bevacizumab were assigned to the "no group").

including social, lifestyle, clinical, tumor-related, and treatment-related characteristics to determine whether associations were explained by these factors. Using the main model (all the previously mentioned factors except treatment), stratified analyses by sex, age at diagnosis, year of diagnosis, cancer site, and disease stage were also conducted. To account for the interval between diagnosis and baseline assessment, lateentry models were computed. ${ }^{21}$ The proportional hazards assumption was assessed for all covariates in the complete case dataset, by examining plots of 
A

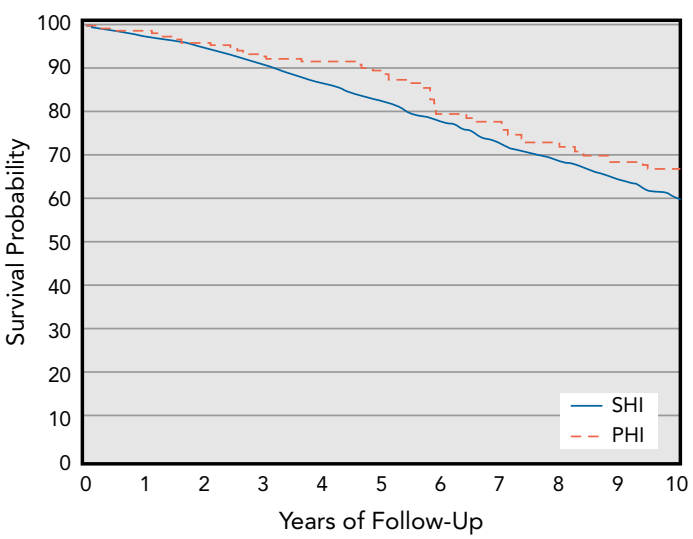

C

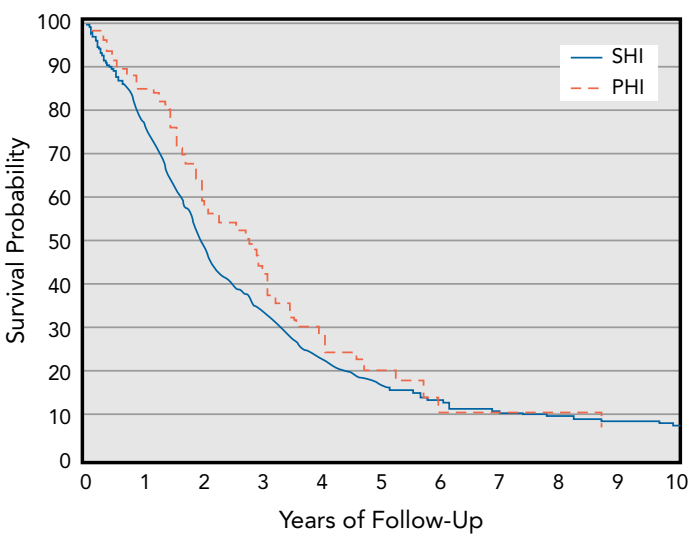

B

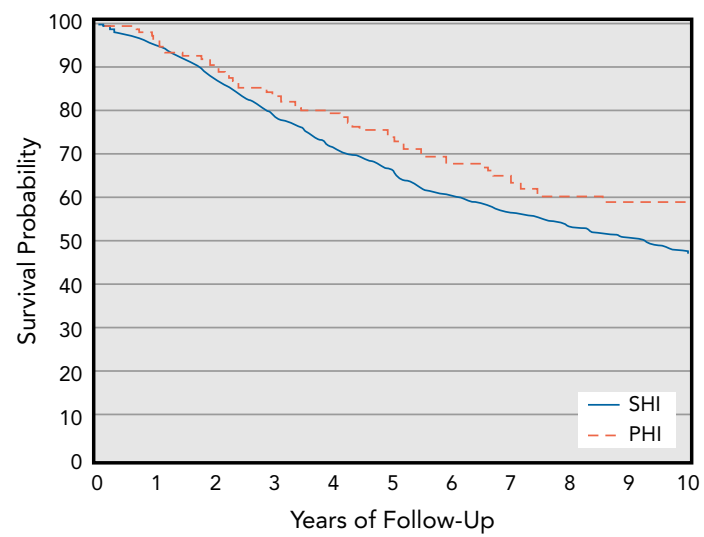

D

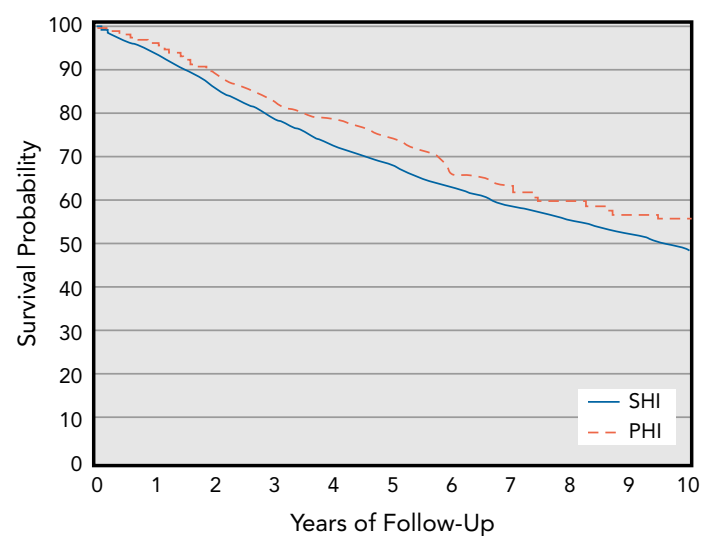

Figure 2. Kaplan-Meier curves showing association of health insurance type with overall survival in patients with colorectal cancer: (A) stages I and II, (B) stage III, (C) stage IV, and (D) all stages.

Abbreviations: $\mathrm{PHI}$, private health insurance; $\mathrm{SHI}$, statutory health insurance.

scaled Schoenfeld residuals and by including a timedependent component.

Multiple imputation was conducted using the MICE package in R. ${ }^{22}$ All other analyses were performed using SAS 9.4 (SAS Institute Inc). Statistical tests were 2-sided, with $\alpha=0.05$.

\section{Results}

A total of 3,977 patients were included in the analyses, $11 \%$ of whom had PHI (supplemental eTable 2). Patients with PHI were more often men, were younger, had a higher level of education, and more often lived with a partner. They also had lower comorbidity and used NSAIDs less often. Furthermore, they were more likely to receive targeted therapy as first-line treatment.

\section{Insurance Type and Treatment Patterns}

Table 1 summarizes results from multivariable analyses on the association of insurance type with first-line treatment administration. Having PHI (vs SHI) was not associated with type of surgery (laparoscopic vs open surgery: odds ratio [OR], 1.17; 95\% CI, $0.87-1.57$ ). It was also not associated with the administration of either adjuvant chemotherapy in patients with stage III colon cancer, oxaliplatin-based chemotherapy in patients with stage III colon cancer aged $<70$ years, or neoadjuvant radiotherapy in patients with stage II-III rectal cancer.

However, in patients with stage IV disease, those with PHI were more likely to receive any targeted therapy (OR, 2.43; 95\% CI, 1.20-4.91) or specifically bevacizumab (OR, 2.46; 95\% CI, 1.26-4.79), the most commonly administered targeted therapy. The difference in administration of targeted therapy essentially reflects a temporal delay in introduction of this therapy among patients with SHI versus PHI, with a tendency for catch-up of patients with SHI in later years, as illustrated in supplemental eFigure 1.

\section{Insurance Type and Survival}

After a median follow-up of 6.3 years, 1,637 patients (41\%) died, 956 of whom died of CRC. Analysis of RFS was restricted to patients with stage I-III disease, with a median follow-up of 4.3 years and 680 events. 
A

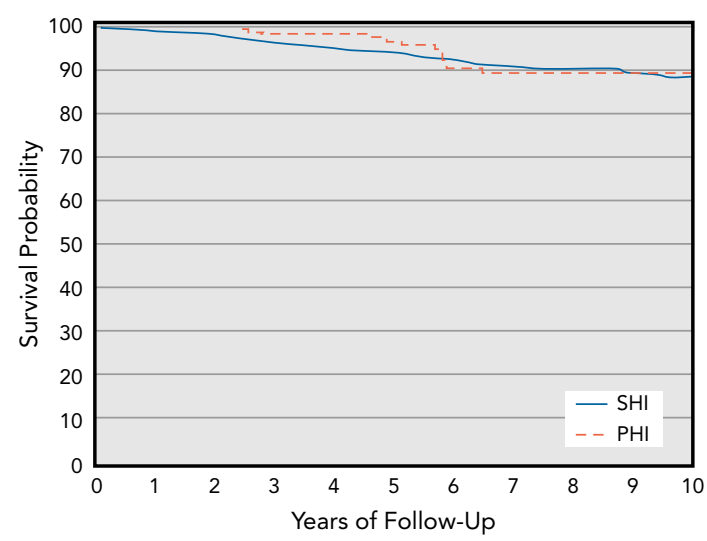

C

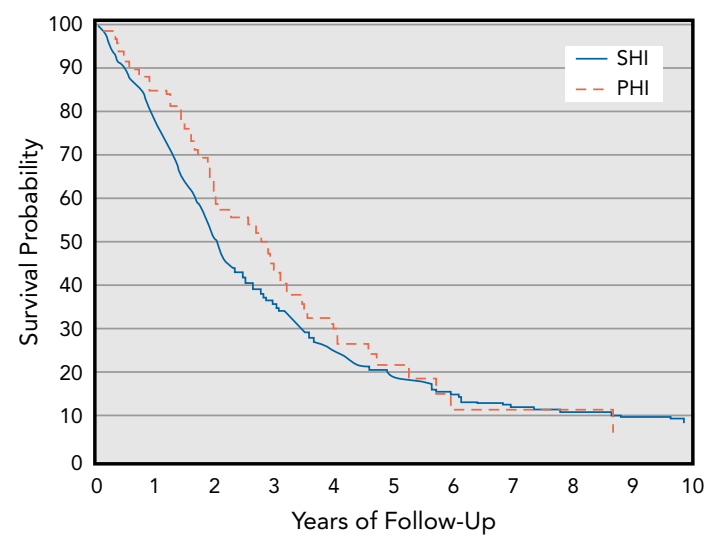

B

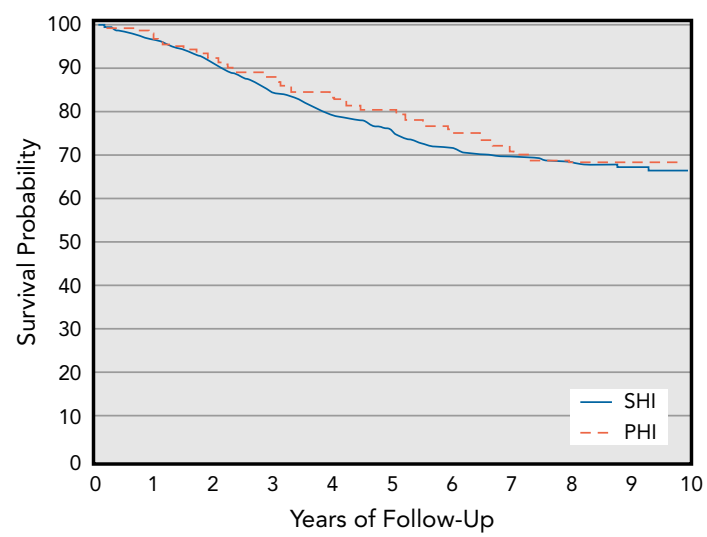

D

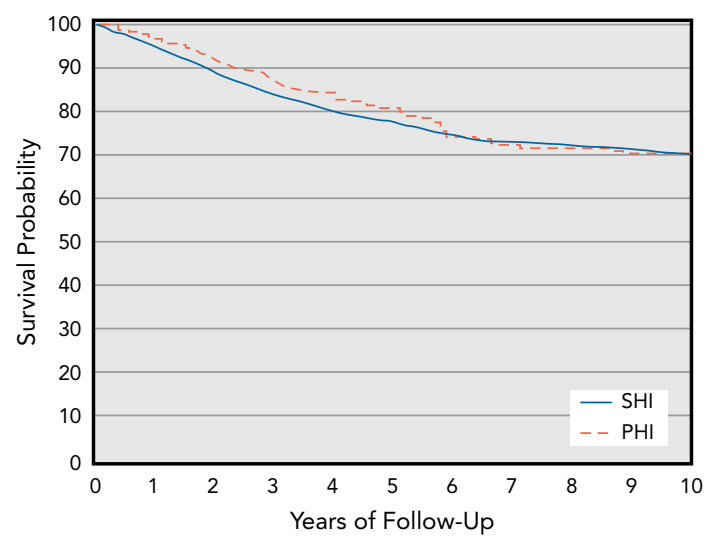

Figure 3. Kaplan-Meier curves showing association of health insurance type with colorectal cancer-specific survival: (A) stages I and II, (B) stage III, (C) stage IV, and (D) all stages.

Abbreviations: $\mathrm{PHI}$, private health insurance; $\mathrm{SHI}$, statutory health insurance.

Kaplan-Meier curves for the associations of insurance type with OS, CSS, and RFS, overall and by tumor stage, are shown in Figures 2-4. Compared with patients with SHI, those with PHI had higher OS, which was consistent within all stages (Figure 2). Median OS for patients with $\mathrm{PHI}$ and SHI were 137.0 and 114.9 months $(P=.010)$, respectively, among those with all disease stages, and 32.7 and 23.3 months $(P=.112)$, respectively, among those with stage IV disease. For CSS and RFS (Figures 3 and 4), survival rates by insurance type were comparable, but patients with stage IV disease with PHI had nonsignificantly longer CSS than those with SHI (median CSS, 33.1 vs 24.1 months; $P=.128)$.

Supplemental eTables 3-5 show the associations of insurance type with survival at different censoring times and after stepwise adjustment for demographic, social, lifestyle, clinical, tumor-related, and treatment factors. Overall, the associations became weaker 5 years after diagnosis. Additionally, the association of insurance type with OS became weaker after adding adjustment factors. No association was, however, observed with CSS or RFS in any of the models. In the main model that included all factors except treatment and with all years of follow-up, HRs for PHI versus SHI were 0.97 (95\% CI, 0.81-1.16), 0.97 (95\% CI, 0.77-1.21), and 0.88 (95\% CI, 0.68-1.14) for OS, CSS, and RFS, respectively (Table 2). Subgroup analyses by sex, age at diagnosis, year of diagnosis, cancer site, and disease stage showed no association between insurance type and survival in any of the stratified groups.

In patients with stage IV disease, recipients of firstline targeted therapy had longer survival than those not receiving such treatment (median OS, 26.6 vs 22.1 months; $P=.004$ ), but this difference became smaller 24 months after diagnosis, and the survival curves canceled each other after approximately 3 years of follow-up (Figure 5). In a multivariable analysis restricted to 24 months from diagnosis, recipients of targeted therapy had nonsignificantly $16 \%$ (HR, 0.84; 95\% CI, 0.62-1.13) 
A

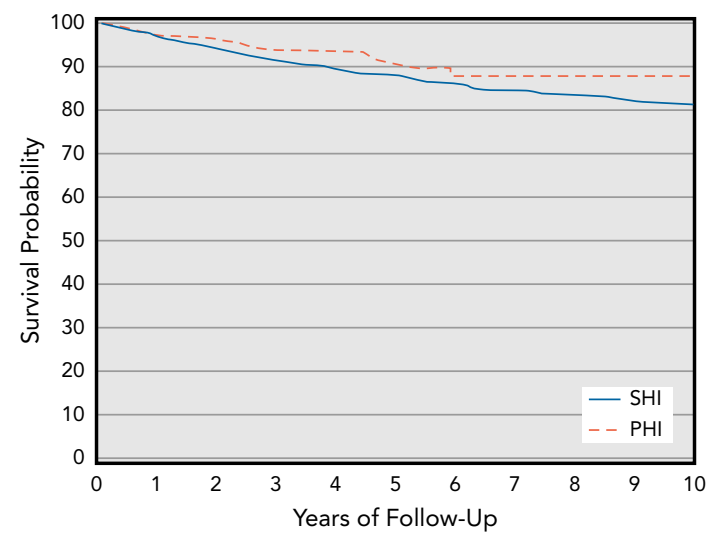

B

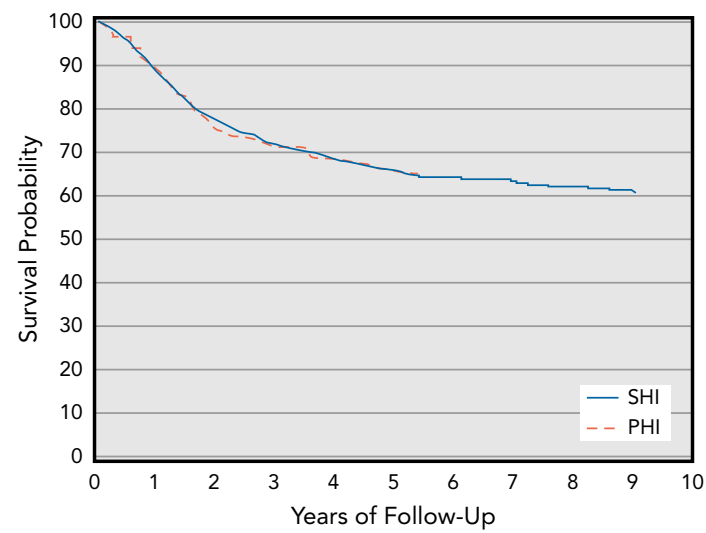

C

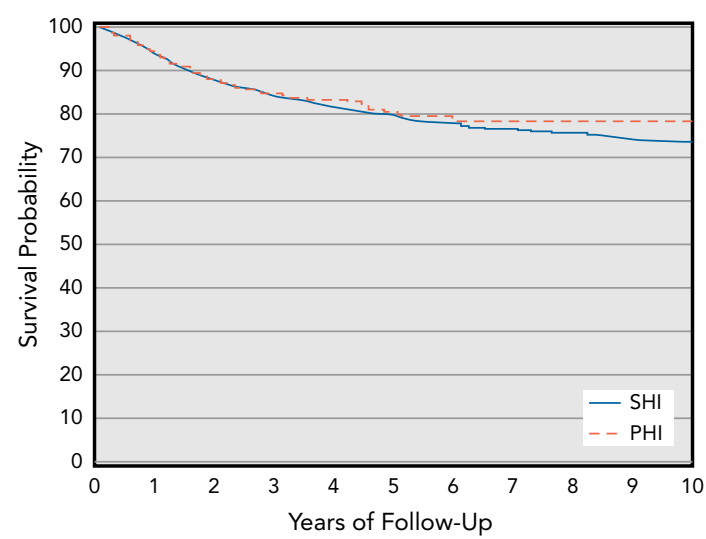

Figure 4. Kaplan-Meier curves showing association of health insurance type with recurrence-free survival in patients with colorectal cancer: (A) stages I and II, (B) stage III, and (C) stages I-III.

Abbreviations: $\mathrm{PHI}$, private health insurance; $\mathrm{SHI}$, statutory health insurance.

lower all-cause and 16\% (HR, 0.84; 95\% CI, 0.62-1.14) lower CRC mortality.

\section{Discussion}

Therapeutic advancement and early detection have played significant roles in the observed improvement in
CRC prognosis in many countries. ${ }^{2,3}$ Targeted therapy is one of the major therapeutic innovations and is increasingly used for treating metastatic CRC in many countries. However, given the high cost of these treatments, their uptake might be influenced by insurance coverage, but such evidence is sparse. We observed substantially higher rates of targeted therapy administration among patients with PHI in the earlier years of the study, with a tendency for catch-up among patients with SHI in the later years. Median OS was longer in patients with PHI versus SHI, but survival advantages in those with stage IV disease were restricted to the earlier years after diagnosis and were explained by differences in sociodemographic factors.

Numerous studies have reported large differences in the waiting times for outpatient and inpatient care between patients with SHI and PHI, with longer waiting times among those with SHI. ${ }^{23-27}$ With respect to treatment, one small study $(n=123)$ showed longer delays between first symptoms and treatment of CRC in publicly insured patients. ${ }^{28}$ However, in that study, insurance status was used as a proxy for socioeconomic status, and it is unclear to what extent the differences were caused by the latter or insurance status itself. Additionally, studies have shown a higher uptake of CRC surgery and use of minimally invasive techniques among privately versus publicly insured patients, even though postoperative complications and survival rates were comparable between the insurance types. ${ }^{29,30}$ Moreover, data from the United States suggest that patients with CRC enrolled on Medicaid, which is a government-regulated insurance type, receive CRC treatments substantially less often and have lower survival than those with PHI. ${ }^{31,32}$ However, whether and to what extent insurance type is associated with uptake of targeted therapy or survival in patients with stage IV disease is unclear but could be useful for determining factors associated with uptake of therapeutic innovations by insurance type in patients with CRC.

We observed large differences in the administration of targeted therapy among patients with stage IV CRC, with approximately $65 \%$ of those with PHI and only $40 \%$ of those with SHI receiving this treatment during the entire period of investigation (2005-2014), with differences seemingly diminishing over time because of catch-up among patients with SHI. The difference by insurance type persisted after adjustment for a large number of relevant factors. Although we cannot determine whether this difference is causally related to insurance type, there are some reasons to support this observation. For example, targeted therapies are expensive and their use is carefully considered by weighing their cost against their benefit using incremental costeffectiveness ratio. However, PHI often does not apply this principle strictly, ${ }^{10}$ potentially increasing the uptake of 


\begin{tabular}{|c|c|c|c|c|c|c|c|c|c|c|c|}
\hline \multirow[b]{2}{*}{ Group } & \multirow[b]{2}{*}{$\mathbf{N}$} & \multicolumn{3}{|c|}{ Overall Survival } & \multicolumn{3}{|c|}{ CRC-Specific Survival } & \multicolumn{4}{|c|}{ Recurrence-Free Survival $^{d}$} \\
\hline & & Event & $\mathrm{HR}(95 \% \mathrm{Cl})^{\mathrm{b}}$ & $\mathrm{HR}(95 \% \mathrm{Cl})^{\mathrm{c}}$ & Event & $\mathrm{HR}(95 \% \mathrm{Cl})^{\mathrm{b}}$ & $\mathrm{HR}(95 \% \mathrm{Cl})^{\mathrm{c}}$ & $\mathbf{N}$ & Event & $\mathrm{HR}(95 \% \mathrm{Cl})^{\mathrm{b}}$ & $\mathrm{HR}(95 \% \mathrm{Cl})^{\mathrm{c}}$ \\
\hline \multicolumn{12}{|l|}{ All } \\
\hline $\mathrm{SHI}$ & 3,550 & 1,487 & Ref & Ref & 858 & Ref & Ref & 3,027 & 611 & Ref & Ref \\
\hline $\mathrm{PHI}$ & 427 & 150 & $0.82(0.69-0.96)$ & $0.97(0.81-1.16)$ & 98 & $0.92(0.75-1.14)$ & $0.97(0.77-1.21)$ & 368 & 69 & $0.93(0.73-1.20)$ & $0.88(0.68-1.14)$ \\
\hline \multicolumn{12}{|l|}{ Male } \\
\hline $\mathrm{SHI}$ & 2,085 & 896 & Ref & Ref & 502 & Ref & Ref & 1,764 & 352 & Ref & Ref \\
\hline $\mathrm{PHI}$ & 289 & 103 & $0.79(0.65-0.97)$ & $0.94(0.76-1.16)$ & 63 & $0.87(0.67-1.14)$ & $0.94(0.71-1.24)$ & 249 & 43 & $0.86(0.63-1.18)$ & $0.85(0.61-1.19)$ \\
\hline \multicolumn{12}{|c|}{ Female } \\
\hline SHI & 1,465 & 591 & Ref & Ref & 356 & Ref & Ref & 1,263 & 259 & Ref & Ref \\
\hline PHI & 138 & 47 & $0.84(0.62-1.12)$ & $1.00(0.73-1.37)$ & 35 & $1.02(0.72-1.45)$ & $0.99(0.68-1.44)$ & 119 & 26 & $1.08(0.72-1.62)$ & $0.91(0.58-1.40)$ \\
\hline \multicolumn{12}{|c|}{$30-69 y$} \\
\hline SHI & 1,670 & 547 & Ref & Ref & 392 & Ref & Ref & 1,393 & 265 & Ref & Ref \\
\hline $\mathrm{PHI}$ & 256 & 71 & $0.81(0.63-1.03)$ & $0.79(0.61-1.03)$ & 55 & $0.87(0.66-1.16)$ & $0.76(0.57-1.03)$ & 214 & 38 & $0.92(0.66-1.30)$ & $0.78(0.55-1.11)$ \\
\hline \multicolumn{12}{|l|}{$\geq 70 y$} \\
\hline $\mathrm{SHI}$ & 1,880 & 940 & Ref & Ref & 466 & Ref & Ref & 1,634 & 346 & Ref & Ref \\
\hline $\mathrm{PHI}$ & 171 & 79 & $0.98(0.78-1.23)$ & $1.13(0.89-1.44)$ & 43 & $1.03(0.76-1.41)$ & $1.23(0.89-1.71)$ & 154 & 31 & $1.00(0.69-1.44)$ & $0.99(0.67-1.46)$ \\
\hline \multicolumn{12}{|c|}{$2003-2008$} \\
\hline $\mathrm{SHI}$ & 1,771 & 919 & Ref & Ref & 495 & Ref & Ref & 1,504 & 351 & Ref & Ref \\
\hline $\mathrm{PHI}$ & 203 & 98 & $0.89(0.73-1.10)$ & $1.08(0.87-1.35)$ & 58 & $0.99(0.75-1.30)$ & $1.08(0.80-1.44)$ & 175 & 42 & $1.04(0.76-1.44)$ & $1.03(0.73-1.45)$ \\
\hline \multicolumn{12}{|c|}{ 2009-2014 } \\
\hline $\mathrm{SHI}$ & 1,779 & 568 & Ref & Ref & 363 & Ref & Ref & 1,524 & 260 & Ref & Ref \\
\hline $\mathrm{PHI}$ & 224 & 52 & $0.71(0.53-0.94)$ & $0.79(0.59-1.06)$ & 40 & $0.85(0.61-1.18)$ & $0.85(0.60-1.20)$ & 193 & 27 & $0.81(0.54-1.20)$ & $0.72(0.47-1.09)$ \\
\hline \multicolumn{12}{|l|}{ Colon } \\
\hline $\mathrm{SHI}$ & 2,236 & 927 & Ref & Ref & 510 & Ref & Ref & 1,914 & 353 & Ref & Ref \\
\hline $\mathrm{PHI}$ & 268 & 93 & $0.81(0.65-1.00)$ & $0.93(0.75-1.16)$ & 58 & $0.91(0.69-1.19)$ & $0.94(0.71-1.24)$ & 230 & 41 & $0.98(0.71-1.36)$ & $0.96(0.68-1.35)$ \\
\hline \multicolumn{12}{|c|}{ Rectum } \\
\hline $\mathrm{SHI}$ & 1,314 & 560 & Ref & Ref & 348 & Ref & Ref & 1,113 & 258 & Ref & Ref \\
\hline $\mathrm{PHI}$ & 159 & 57 & $0.82(0.63-1.08)$ & $0.99(0.74-1.34)$ & 40 & $0.95(0.68-1.32)$ & $0.99(0.68-1.43)$ & 138 & 28 & $0.84(0.57-1.25)$ & $0.75(0.50-1.13)$ \\
\hline \multicolumn{12}{|c|}{ Stages I-II } \\
\hline $\mathrm{SHI}$ & 1,916 & 564 & Ref & Ref & 148 & Ref & Ref & 1,183 & 196 & Ref & Ref \\
\hline $\mathrm{PHI}$ & 222 & 51 & $0.77(0.58-1.03)$ & $0.92(0.69-1.24)$ & 14 & $0.85(0.50-1.46)$ & $0.97(0.56-1.70)$ & 222 & 19 & $0.75(0.48-1.18)$ & $0.74(0.47-1.17)$ \\
\hline \multicolumn{12}{|c|}{ Stage III } \\
\hline $\mathrm{SHI}$ & 1,135 & 488 & Ref & Ref & 300 & Ref & Ref & 1,124 & 372 & Ref & Ref \\
\hline $\mathrm{PHI}$ & 146 & 49 & $0.74(0.55-0.99)$ & $0.96(0.70-1.33)$ & 35 & $0.87(0.61-1.23)$ & $0.89(0.61-1.29)$ & 146 & 48 & $0.99(0.73-1.34)$ & $0.97(0.70-1.34)$ \\
\hline \multicolumn{12}{|c|}{ Stage IV } \\
\hline $\mathrm{SHI}$ & 503 & 435 & Ref & Ref & 410 & Ref & Ref & & & d & d \\
\hline $\mathrm{PHI}$ & 59 & 50 & $0.86(0.64-1.16)$ & $1.01(0.74-1.39)$ & 48 & $0.89(0.66-1.20)$ & $1.03(0.74-1.42)$ & & & d & d \\
\hline
\end{tabular}

Bold indicates statistically significant results.

Abbreviations: CRC, colorectal cancer; HR, hazard ratio; PHI, private health insurance; SHI, statutory health insurance.

aEstimates are for all years of follow-up.

${ }^{b}$ Crude estimates.

'Adjusted for sex, age at diagnosis, years of schooling, living with a partner, lifestyle score, Charlson comorbidity score, regular use of statins, regular use of nonsteroidal anti-inflammatory drugs, year of diagnosis, and cancer stage and site.

${ }^{\mathrm{d}}$ Analysis of recurrence-free survival was restricted to patients with stage I-III disease.

therapeutic innovations by patients with PHI compared with those with SHI.

In our study, median OS for recipients and nonrecipients of targeted therapy was 26.6 and 22.1 months, respectively, and bevacizumab was the most frequently administered targeted therapy. However, the use of bevacizumab has been highly debated in recent years. For example, in one clinical trial, the addition 


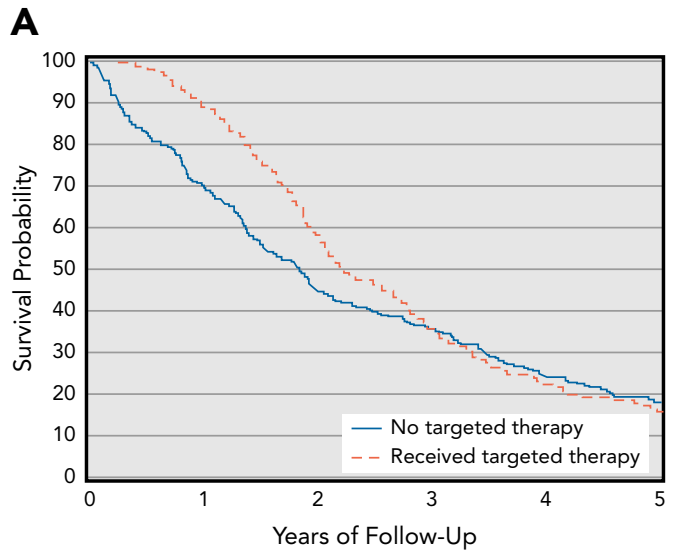

B

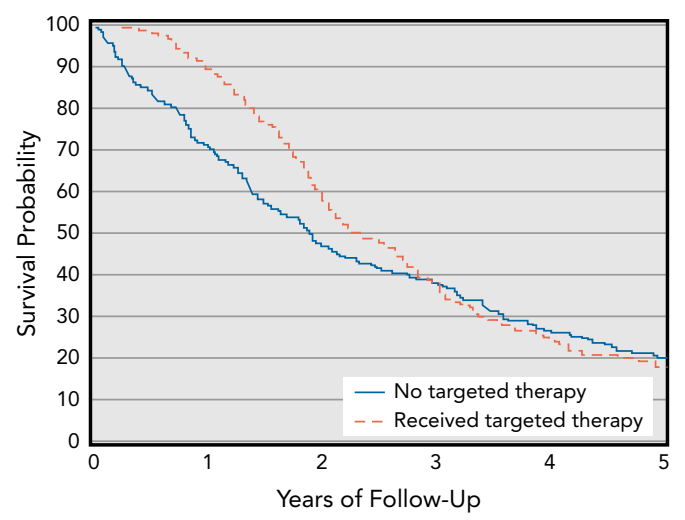

Figure 5. Kaplan-Meier curves showing the association of targeted therapy with (A) overall survival and (B) CRC-specific survival in patients with stage IV CRC. Analysis was restricted to years of diagnosis $\geq 2005$, because no patient received targeted therapy before 2005. Due to small numbers, the curves were truncated at 5 years of follow-up.

Abbreviation: CRC, colorectal cancer.

of bevacizumab to irinotecan/5-FU/leucovorin (LV) increased the median progression-free survival from 6.2 to 10.6 months. ${ }^{33}$ However, in a later trial that used oxaliplatin-based therapy (5-FU/LV + oxaliplatin [FOLFOX-4]) as the reference regimen, the net survival benefit added by bevacizumab was only 1.4 months. ${ }^{34}$ This indicates that the benefit of bevacizumab depends on the chemotherapy regimen being compared and thus needs further investigation. ${ }^{7,35}$ Additionally, bevacizumab is associated with higher rates of adverse effects (eg, grade III/IV hypertension), ${ }^{35}$ and cost-effectiveness analyses from several countries suggest that adding bevacizumab to standard first-line treatments in patients with stage IV CRC is not cost-effective in terms of life years gained. ${ }^{36,37}$

We observed no significant differences in administration of first-line CRC treatments, including surgery, chemotherapy, and radiotherapy, in patients with stage I-III disease, suggesting that treatment patterns for this patient population are similar, irrespective of insurance status. This observation is plausible because these treatments are recommended in the treatment guidelines for CRC in Germany, ${ }^{18,19}$ and this finding suggests that both insurance types strive to ensure equitable access to cancer care whenever possible. This finding also suggests that SHI may approve the most valuable treatments for patients with CRC in a timely manner, but there may be possible delays in approval for treatments that have marginal benefits. This may ensure efficient budget expenditure and prioritization of healthcare resources for various diseases, given that most of the German population $(\sim 89 \%)$ is dependent on SHI.

Major strengths of our study include the use of population-based data with almost complete treatment information, detailed assessment of confounders (eg, comorbidities), and a long follow-up of patients. We also computed late-entry models to account for the interval between diagnosis and baseline assessment, ${ }^{21}$ thereby minimizing delayed entry bias.

Our study also has limitations. First, there was an age gradient in patient recruitment in the DACHS study, with higher recruitment rates among younger patients, who in our analysis were more likely to have PHI than SHI. However, the proportion of participants with PHI (11\%) was similar to that of the general population. ${ }^{9}$ Second, approximately $19 \%$ of the DACHS participants could not be included in our analysis because of missing data on insurance status. Most of the excluded patients were treated in an academic institution $(83 \%)$ and differed from the included sample to some extent (supplemental eTable 6). For example, excluded patients were somewhat younger, had a higher level of education, and more often had more advanced-staged tumors compared with included patients. Our results might thus be less applicable to populations receiving treatment in academic institutions. However, it is worth mentioning that availability of insurance data in the DACHS study was dependent on agreement of the participating hospitals. Hence, missing data were due to administrative reasons only. Third, we could not determine whether nontreatment was due to patient preference or physician recommendation. This aspect is particularly important for patients with stage IV disease, in whom treatment is more individualized and strongly depends on patient preferences. Fourth, we could not investigate the role of more recently developed targeted therapies (nonbevacizumab treatments, such as panitumumab) in patient survival because of the small number of recipients $(n=45 ; S H I=38$ and $\mathrm{PHI}=7)$. Lastly, analyses of potential differences in second-line and third-line treatments would also be of interest, but the data in our study were not sufficient to perform such analysis. 


\section{Conclusions}

In this cohort of patients with CRC recruited in a population-based setting in Germany, we found higher rates of administration of novel therapies such as targeted therapy in privately insured patients with stage IV CRC than in those with public insurance in the earlier years, with a tendency for catch-up of patients with public insurance in the later years. Median OS was longer in patients with PHI than those with SHI, but survival advantages were explained by differences in sociodemographic factors. Among patients with stage IV disease, survival benefits of targeted therapy were restricted to the early years after diagnosis. As therapeutic innovations in CRC continue, targeted therapies are likely to be used more frequently in the future. Our findings thus warrant further investigation to determine key factors associated with uptake of novel therapies and survival by insurance type in patient groups eligible for such treatments.

\section{Acknowledgments}

We would like to thank Ute Handte-Daub, Ansgar Brandhorst, and Petra Bächer for their excellent technical assistance. We are particularly grateful to the study participants, as well as the interviewers who assisted in the data collection. We also gratefully appreciate the cooperation of the following clinics and institutions: Chirurgische Universitätsklinik Heidelberg, Klinik am
Gesundbrunnen Heilbronn, St. Vincentiuskrankenhaus Speyer, St. Josefskrankenhaus Heidelberg, Chirurgische Universitätsklinik Mannheim, Diakonissenkrankenhaus Speyer, Krankenhaus Salem Heidelberg, Kreiskrankenhaus Schwetzingen, St. Marienkrankenhaus Ludwigshafen, Klinikum Ludwigshafen, Stadtklinik Frankenthal, Diakoniekrankenhaus Mannheim, Kreiskrankenhaus Sinsheim, Klinikum am Plattenwald Bad Friedrichshall, Kreiskrankenhaus Weinheim, Kreiskrankenhaus Eberbach, Kreiskrankenhaus Buchen, Kreiskrankenhaus Mosbach, Enddarmzentrum Mannheim, Kreiskrankenhaus Brackenheim, and Cancer Registry of Rhineland-Palatinate, Mainz.

Submitted April 30, 2020; accepted for publication August 7, 2020. Published online February 12, 2021

Author contributions: Study concept and design: Jansen, Brenner. Data acquisition and coordination: Jansen, Boakye, Alwers, Carr, Chang-Claude, Hoffmeister, Brenner. Data analysis and interpretation: Jansen, Boakye, Hoffmeister, Brenner. Manuscript preparation: Jansen, Boakye, Brenner. Critical revision: All authors.

Disclosures: Dr. Martens has disclosed that he was a scientific advisor for Amgen, Roche, Merck, Bristol-Myers Squibb, and Merck Sharp and Dohme. The remaining authors have disclosed that they have no financial interests, arrangements, affiliations, or commercial interests with the manufacturers of any products discussed in this article or their competitors.

Funding: This work was supported by grants from the German Research Council (BR 1704/6-1, BR 1704/6-3, BR 1704/6-4, CH 117/1-1), German Federal Ministry of Education and Research (01KH0404, 01ER0814, 01ER0815, 01ER1505A, 01ER1505B), and the Ministry of Science, Research and Arts of Baden-Wuerttemberg

Correspondence: Lina Jansen, MSc, PhD, Division of Clinical Epidemiology and Aging Research, German Cancer Research Center (DKFZ), Im Neuenheimer Feld 581, 69120 Heidelberg, Germany. Email: I.jansen@dkfz.de

\section{References}

1. Bray F, Ferlay J, Soerjomataram I, et al. Global cancer statistics 2018: GLOBOCAN estimates of incidence and mortality worldwide for 36 cancers in 185 countries. CA Cancer J Clin 2018;68:394-42.

2. Ait Ouakrim D, Pizot C, Boniol M, et al. Trends in colorectal cancer mortality in Europe: retrospective analysis of the WHO mortality database. BMJ 2015;351:h4970.

3. American Cancer Society. Colorectal Cancer Facts \& Figures 2017-2019. Atlanta, GA: American Cancer Society; 2017.

4. Robert Koch-Institut. Krebs in Deutschland 2015/2016. Berlin, Germany; Robert Koch-Institut; 2019.

5. Hsu JC, Lu CY. Longitudinal trends in use and costs of targeted therapies for common cancers in Taiwan: a retrospective observational study. BMJ Open 2016;6:e011322

6. Ilic I, Jankovic S, Ilic M. Bevacizumab combined with chemotherapy improves survival for patients with metastatic colorectal cancer: evidence from meta analysis. PLoS One 2016;11:e0161912.

7. Botrel TEA, Clark LGO, Paladini L, et al. Efficacy and safety of bevacizumab plus chemotherapy compared to chemotherapy alone in previously untreated advanced or metastatic colorecta cancer: a systematic review and meta-analysis. BMC Cancer 2016;16:677

8. Busse R, Blümel M, Knieps F, et al. Statutory health insurance in Germany: a health system shaped by 135 years of solidarity, self-governance, and competition. Lancet 2017;390:882-897.

9. Thomson $\mathrm{S}$, Osborn R, Squires D, et al. International profiles of health care systems, 2013: Australia, Canada, Denmark, England, France, Germany, Italy, Japan, the Netherlands, New Zealand, Norway, Sweden, Switzerland, and the United States. Accessed August 29, 2019. Available at: https://www.commonwealthfund.org/sites/default/files/documents/ media_files_publications_fund_report_2013_nov_1717_thomson_intl_ profiles_hlt_care_sys_2013_v2.pdf

10. Greß S. Private health insurance in Germany: consequences of a dual system. Healthc Policy 2007;3:29-37.
11. Brenner $\mathrm{H}$, Chang-Claude J, Jansen $\mathrm{L}$, et al. Reduced risk of colorectal cancer up to 10 years after screening, surveillance, or diagnostic colonoscopy. Gastroenterology 2014;146:709-717.

12. Hoffmeister $M$, Jansen $L$, Rudolph $A$, et al. Statin use and survival after colorectal cancer: the importance of comprehensive confounder adjustment. J Natl Cancer Inst 2015;107:djv045.

13. Carr PR, Weigl $K$, Jansen $L$, et al. Healthy lifestyle factors associated with lower risk of colorectal cancer irrespective of genetic risk. Gastroenterology 2018;155:1805-1815.e5.

14. Charlson ME, Pompei $P$, Ales $K L$, et al. A new method of classifying prognostic comorbidity in longitudinal studies: development and validation. J Chronic Dis 1987;40:373-383.

15. Deyo RA, Cherkin DC, Ciol MA. Adapting a clinical comorbidity index for use with ICD-9-CM administrative databases. J Clin Epidemiol 1992;45:613-619.

16. Boakye D, Walter $V$, Jansen $L$, et al. Magnitude of the age-advancement effect of comorbidities in colorectal cancer prognosis. J Natl Compr Canc Netw 2020;18:59-68.

17. Sobin LH, Wittekind C. TNM Classification of Malignant Tumours, 6th ed. Hoboken, NJ: John Wiley \& Sons; 2002.

18. Pox C, Aretz S, Bischoff SC, et al. [S3-guideline colorectal cancer version 1.0]. Z Gastroenterol 2013;51:753-854 [in German].

19. Schmiegel W, Reinacher-Schick A, Arnold D, et al. [Update S3-guideline "colorectal cancer" 2008]. Z Gastroenterol 2008;46:799-840 [in German].

20. Schemper M, Smith TL. A note on quantifying follow-up in studies of failure time. Control Clin Trials 1996;17:343-346.

21. Matsuura M, Eguchi S. Modeling late entry bias in survival analysis. Biometrics 2005;61:559-566.

22. van Buuren S, Groothuis-Oudshoorn K. mice: Multivariate Imputation by Chained Equations in R. J Stat Softw 2011;45:1-67.

23. Kuchinke BA, Sauerland D, Wübker A. The influence of insurance status on waiting times in German acute care hospitals: an empirical analysis of new data. Int J Equity Health 2009;8:44. 
24. Lungen $M$, Stollenwerk B, Messner $P$, et al. Waiting times for elective treatments according to insurance status: a randomized empirical study in Germany. Int J Equity Health 2008;7:1.

25. Schwierz C, Wübker A, Wübker A, et al. Discrimination in waiting times by insurance type and financial soundness of German acute care hospitals. Eur J Health Econ 2011;12:405-416.

26. Luque Ramos A, Hoffmann F, Spreckelsen $O$. Waiting times in primary care depending on insurance scheme in Germany. BMC Health Serv Res 2018; 18:191.

27. Sundmacher $L$, Kopetsch $T$. Waiting times in the ambulatory sector-the case of chronically ill patients. Int J Equity Health 2013;12:77.

28. Langenbach MR, Sauerland S, Kröbel KW, et al. Why so late?!-delay in treatment of colorectal cancer is socially determined. Langenbecks Arch Surg 2010;395:1017-1024.

29. Hall SE, Holman CDAJ, Platell C, et al. Colorectal cancer surgical care and survival: do private health insurance, socioeconomic and locational status make a difference? ANZ J Surg 2005;75:929-935.

30. Schneider MA, Rickenbacher A, Frick L, et al. Insurance status does not affect short-term outcomes after oncological colorectal surgery in Europe, but influences the use of minimally invasive techniques: a propensity score-matched analysis. Langenbecks Arch Surg 2018; 403:863-872.
31. Ward E, Halpern M, Schrag N, et al. Association of insurance with cancer care utilization and outcomes. CA Cancer J Clin 2008;58:9-31.

32. Sun $W$, Cheng $M$, Zhuang $S$, et al. Impact of insurance status on stage treatment, and survival in patients with colorectal cancer: a populationbased analysis. Med Sci Monit 2019;25:2397-2418.

33. Hurwitz H, Fehrenbacher L, Novotny W, et al. Bevacizumab plus irinotecan, fluorouracil, and leucovorin for metastatic colorectal cancer. N Engl J Med 2004;350:2335-2342.

34. Saltz LB, Clarke S, Díaz-Rubio $E$, et al. Bevacizumab in combination with oxaliplatin-based chemotherapy as first-line therapy in metastatic colorectal cancer: a randomized phase III study. J Clin Oncol 2008;26: 2013-2019.

35. Wagner AD, Arnold D, Grothey AA, et al. Anti-angiogenic therapies for metastatic colorectal cancer. Cochrane Database Syst Rev 2009;3: CD005392.

36. Tappenden $\mathrm{P}$, Jones $\mathrm{R}$, Paisley $\mathrm{S}$, et al. The cost-effectiveness of bevacizumab in the first-line treatment of metastatic colorectal cancer in England and Wales. Eur J Cancer 2007;43:2487-2494.

37. Goldstein DA, Chen Q, Ayer T, et al. Bevacizumab for metastatic colorectal cancer: a global cost-effectiveness analysis. Oncologist 2017;22 694-699.

\section{See JNCCN.org for supplemental online content.}


Supplemental online content for:

\section{Uptake Rates of Novel Therapies and Survival Among Privately Insured Versus Publicly Insured Patients With Colorectal Cancer in Germany}

Lina Jansen, MSc, PhD; Daniel Boakye, PhD, MPH; Elizabeth Alwers, MSc, MD; Prudence R. Carr, MSc, PhD; Christoph Reissfelder, MD; Martin Schneider, MD; Uwe M. Martens, MD; Jenny Chang-Claude, MSc, PhD; Michael Hoffmeister, MSc, PhD; and Hermann Brenner, MD, MPH

J Natl Compr Canc Netw 2021;19(4):411-420

eAppendix 1: Supplemental Methods: Multiple Imputation

eTable 1: Overview of Imputed Factors by Insurance Type After Multiple Imputation

eTable 2: Patient Characteristics

eTable 3: Association of Insurance Type With Overall Survival

eTable 4: Association of Insurance Type With CRC-Specific Survival

eTable 5: Association of Insurance Type With Recurrence-Free Survival

eTable 6: Comparison of Patient Characteristics Between Included and Excluded Participants

eFigure 1: Proportion of Patients With Who Received First-Line Chemotherapy With or Without Targeted Therapy 


\section{eAppendix 1. Supplemental Methods: Multiple Imputation}

Before multivariable analyses, multiple imputation was conducted using the multivariate imputation by chained equation (MICE) method. ${ }^{1}$ Convergence of the model was checked graphically. The imputation model included all variables included in the analyses. For the lifestyle score and tumor stage, the original variables (eg, T, N, and M classification and individual lifestyle factors) instead of the aggregated variables were included. The Nelson estimator was used to estimate follow-up time. ${ }^{2}$ The distributions of the imputed factors were overall similar to the distribution after excluding patients with missing values (eTable 1 ; all deviations were $<0.07 \%$ units). In multivariable analyses, results computed on the single datasets $(\mathrm{N}=50)$ were pooled using the PROC MIANALZE function in SAS 9.4 (SAS Institute Inc).

\footnotetext{
References

1. van Buuren S, Groothuis-Oudshoorn K. MICE: Multivariate Imputation by Chained Equations in R. J Stats Softw 2011;45:1-67.

2. White IR, Royston P. Imputing missing covariate values for the Cox model. Stat Med 2009;28:1982-1998.
} 


\section{eTable 1. Overview of Imputed Factors by \\ Insurance Type After Multiple \\ Imputation}

\begin{tabular}{|lcc|}
\hline Factor & SHI, \% & PHI, \% \\
\hline $\begin{array}{l}\text { Social } \\
\text { Years of schooling }\end{array}$ & \\
\hline$<9 y$ & 71.7 & 36.5 \\
\hline $9-10 y$ & 16.5 & 23.7 \\
\hline$>10 y$ & 11.9 & 39.8
\end{tabular}

Lifestyle

Lifestyle score

\begin{tabular}{lll} 
Meet 0-2 recommendations & 31.4 & 27.8 \\
\hline Meet 3 recommendations & 36.0 & 35.8 \\
\hline Meet 4-5 recommendations & 32.6 & 36.4
\end{tabular}

Clinical

Use of statins ${ }^{\mathrm{a}}$

\begin{tabular}{lll}
\hline No & 83.9 & 86.4 \\
\hline Yes & 16.1 & 13.6
\end{tabular}

Use of NSAIDs ${ }^{b}$

\begin{tabular}{lll}
\hline No & 70.8 & 76.5 \\
\hline Yes & 29.2 & 23.5
\end{tabular}

Tumor-related

Cancer stage

$\begin{array}{lll}\text { I } & 23.1 & 22.4\end{array}$

II $\quad 30.8 \quad 29.4$

III $\quad 32.0 \quad 34.3$

IV $14.2 \quad 13.8$

Treatment

\begin{tabular}{lrc}
\hline Type of surgeryc & & \\
\hline None & 1.8 & 1.4 \\
\hline Open & 83.6 & 79.8 \\
\hline Laparoscopic & 14.6 & 18.8 \\
\hline Radiotherapy ${ }^{d}$ & & \\
\hline No & 84.4 & 84.5 \\
\hline Yes & 15.6 & 15.5 \\
\hline Chemotherapyd & & 52.5 \\
\hline No & 55.8 & 47.5 \\
\hline Yes & 44.2 & \\
\hline Targeted therapy ${ }^{d, e}$ & & 90.2 \\
\hline No & 94.5 & 9.8 \\
\hline Yes & 5.5 & \\
\hline
\end{tabular}

Abbreviations: NSAIDs, nonsteroidal anti-inflammatory drugs; $\mathrm{PHI}$, private health insurance; SHI, statutory health insurance.

a Use of statin was defined as current use of statin more than once per week.

bUse of NSAIDs was defined as taking NSAIDs at least 2 times per week for at least 1 year before diagnosis.

'Laparoscopic surgeries include laparoscopic surgeries that were converted to open surgeries.

dFirst-line adjuvant or neoadjuvant treatment.

eOne patient was excluded as no information on immunotherapy was available and information could not be reliably imputed from the complete variables. 


\section{eTable 2. Patient Characteristics}

\begin{tabular}{|c|c|c|c|c|}
\hline Variable $^{a}$ & Total n (\%) & SHI n (\%) & PHI n (\%) & $\begin{array}{c}P \\
\text { Value }\end{array}$ \\
\hline Patients, N & 3,977 & 3,550 & 427 & \\
\hline \multicolumn{5}{|l|}{ Demographic } \\
\hline Sex & & & & .0004 \\
\hline Female & $1,603(40.3)$ & $1,465(41.3)$ & $138(32.3)$ & \\
\hline Male & $2,374(59.7)$ & $2,085(58.7)$ & $289(67.7)$ & \\
\hline \multicolumn{2}{|l|}{ Age at diagnosis, $y$} & & & $<.0001$ \\
\hline $30-59$ & $776(19.5)$ & $677(19.1)$ & $99(23.2)$ & \\
\hline $60-69$ & $1,150(28.9)$ & $993(28.0)$ & $157(36.8)$ & \\
\hline $70-79$ & $1,368(34.4)$ & $1,251(35.2)$ & $117(27.4)$ & \\
\hline$\geq 80$ & $683(17.2)$ & $629(17.7)$ & $54(12.6)$ & \\
\hline Median (IQR) & $70(62-77)$ & $70(62-77)$ & $67(60-74)$ & \\
\hline \multicolumn{5}{|l|}{ Social } \\
\hline \multicolumn{2}{|c|}{ Years of school education } & & & $<.0001$ \\
\hline$<9 y$ & $2,695(67.9)$ & $2,539(71.7)$ & $156(36.5)$ & \\
\hline $9-10 y$ & $684(17.2)$ & $583(16.5)$ & $101(23.7)$ & \\
\hline$>10 y$ & $590(14.9)$ & $420(11.9)$ & $170(39.8)$ & \\
\hline \multicolumn{2}{|l|}{ Living with a partner } & & & .0011 \\
\hline No & $1,054(26.5)$ & $969(27.3)$ & $85(20.0)$ & \\
\hline Yes & $2,918(73.4)$ & $2,577(72.7)$ & $341(80.0)$ & \\
\hline \multicolumn{5}{|l|}{ Lifestyle } \\
\hline \multicolumn{2}{|l|}{ Lifestyle score } & & & .16 \\
\hline $\begin{array}{l}\text { Meet } 0-2 \\
\text { recommendations }\end{array}$ & $1,159(30.7)$ & $1,045(31.1)$ & $114(27.3)$ & \\
\hline $\begin{array}{l}\text { Meet } 3 \\
\text { recommendations }\end{array}$ & $1,362(36.1)$ & $1,213(36.1)$ & 149 (35.7) & \\
\hline $\begin{array}{l}\text { Meet } 4-5 \\
\text { recommendations }\end{array}$ & $1,255(33.2)$ & $1,101(32.8)$ & $154(36.9)$ & \\
\hline \multicolumn{5}{|l|}{ Clinical } \\
\hline \multicolumn{2}{|l|}{ Comorbidity $(\mathrm{CCl} \text { score })^{b}$} & & & $<.0001$ \\
\hline None (0) & $2,192(55.1)$ & $1,911(53.8)$ & $281(65.8)$ & \\
\hline Mild (1) & $859(21.6)$ & $786(22.1)$ & $73(17.1)$ & \\
\hline $\begin{array}{l}\text { Moderate/Severe } \\
(\geq 2)\end{array}$ & $926(23.3)$ & $853(24.0)$ & $73(17.1)$ & \\
\hline \multicolumn{2}{|l|}{ Use of statins ${ }^{c}$} & & & .19 \\
\hline No & $3,345(84.2)$ & $2,976(83.9)$ & $369(86.4)$ & \\
\hline Yes & $627(15.8)$ & $569(16.1)$ & $58(13.6)$ & \\
\hline \multicolumn{2}{|l|}{ Use of NSAIDs ${ }^{d}$} & & & .0131 \\
\hline No & $2,800(71.4)$ & $2,476(70.8)$ & $324(76.6)$ & \\
\hline Yes & $1,119(28.6)$ & $1,020(29.2)$ & $99(23.4)$ & \\
\hline
\end{tabular}

(continued)

\section{eTable 2. Patient Characteristics (cont.)}

\begin{tabular}{|c|c|c|c|c|}
\hline Variable $^{a}$ & Total n (\%) & SHI n (\%) & PHI n (\%) & $\begin{array}{c}P \\
\text { Value }\end{array}$ \\
\hline \multicolumn{5}{|l|}{ Tumor-related } \\
\hline Year of diagnosis & & & & .53 \\
\hline 2003-2006 & $1,314(33.0)$ & $1,180(33.2)$ & $134(31.4)$ & \\
\hline 2007-2010 & $1,342(33.7)$ & 1,201 (33.8) & $141(33.0)$ & \\
\hline 2011-2014 & 1,321 (33.2) & 1,169 (32.9) & $152(35.6)$ & \\
\hline Cancer stage & & & & .84 \\
\hline I & $873(22.7)$ & $781(22.8)$ & $92(22.5)$ & \\
\hline II & $1,188(31.0)$ & $1,067(31.1)$ & $121(29.6)$ & \\
\hline III & $1,221(31.8)$ & $1,083(31.6)$ & $138(33.7)$ & \\
\hline IV & $556(14.5)$ & $498(14.5)$ & $58(14.2)$ & \\
\hline Cancer site & & & & .93 \\
\hline Colon & $1,473(37.0)$ & $1,314(37.0)$ & $159(37.2)$ & \\
\hline $\begin{array}{l}\text { Rectosigmoid/ } \\
\text { Rectum }\end{array}$ & $2,504(63.0)$ & $2,236(63.0)$ & $268(62.8)$ & \\
\hline \multicolumn{5}{|l|}{ Treatment } \\
\hline Type of surgerye & & & & .07 \\
\hline None & $70(1.8)$ & $64(1.8)$ & $6(1.4)$ & \\
\hline Open & 3,303 (83.2) & $2,963(83.6)$ & $340(79.8)$ & \\
\hline Laparoscopic & $598(15.1)$ & $518(14.6)$ & $80(18.8)$ & \\
\hline Radiotherapy ${ }^{f}$ & & & & .97 \\
\hline No & $3,350(84.4)$ & $2,990(84.4)$ & $360(84.3)$ & \\
\hline Yes & $620(15.6)$ & $553(15.6)$ & $67(15.7)$ & \\
\hline Chemotherapy ${ }^{f}$ & & & & .18 \\
\hline No & $2,205(55.5)$ & 1,981 (55.9) & $224(52.5)$ & \\
\hline Yes & $1,765(44.5)$ & $1,562(44.1)$ & $203(47.5)$ & \\
\hline Targeted therapy ${ }^{f}$ & & & & .0003 \\
\hline No & $3,737(94.0)$ & $3,352(94.5)$ & $385(90.2)$ & \\
\hline Yes & $237(6.0)$ & $195(5.5)$ & $42(9.8)$ & \\
\hline
\end{tabular}

Abbreviations: $\mathrm{CCl}$, Charlson comorbidity index; IQR, interquartile range; NSAIDs, nonsteroidal anti-inflammatory drugs; PHI, private health insurance; SHI, statutory health insurance.

aNumber of missing values: years of school education $(n=8)$, living with a partner $(n=5)$, lifestyle score $(n=201)$, statin use $(n=5)$, use of NSAIDs $(n=58)$, cancer stage $(n=139)$, type of surgery $(n=6)$, radiotherapy $(n=7)$, chemotherapy $(n=7)$, and targeted therapy $(n=3)$.

b Charlson comorbidity score was calculated based on comorbidities at diagnosis.

CUse of statin was defined as current use of statin more than once per week. dUse of NSAIDs was defined as taking NSAIDs at least 2 times per week for at least 1 year before diagnosis.

eLaparoscopic surgeries include laparoscopic surgeries that were converted to open surgeries.

${ }^{\mathrm{f}}$ First-line adjuvant or neoadjuvant treatment. 
eTable 3. Association of Insurance Type With Overall Survival

\begin{tabular}{|c|c|c|c|c|c|c|}
\hline Group & $\begin{array}{l}\text { Insurance } \\
\text { Type }\end{array}$ & $\begin{array}{l}\text { At } 2 \text { Years } \\
\text { HR }(95 \% \mathrm{Cl})\end{array}$ & $\begin{array}{l}\text { At } 3 \text { Years } \\
\text { HR }(95 \% \mathrm{Cl})\end{array}$ & $\begin{array}{l}\text { At } 5 \text { Years } \\
\text { HR }(95 \% \mathrm{Cl})\end{array}$ & $\begin{array}{l}\text { At } 10 \text { Years } \\
\text { HR }(95 \% \mathrm{Cl})\end{array}$ & $\begin{array}{c}\text { All Years } \\
\text { HR }(95 \% \mathrm{Cl})\end{array}$ \\
\hline \multicolumn{7}{|l|}{ All stages } \\
\hline Crude & $\mathrm{PHI}$ vs SHI & $0.79(0.59-1.06)$ & $0.80(0.63-1.01)$ & $0.78(0.64-0.95)$ & $0.81(0.66-0.96)$ & $0.82(0.69-0.96)$ \\
\hline Demographic & PHI vs SHI & $0.85(0.63-1.15)$ & $0.86(0.68-1.10)$ & $0.84(0.69-1.03)$ & $0.88(0.74-1.05)$ & $0.87(0.74-1.03)$ \\
\hline + Social & $\mathrm{PHI}$ vs SHI & $0.89(0.66-1.21)$ & $0.88(0.69-1.13)$ & $0.85(0.69-1.05)$ & $0.91(0.76-1.08)$ & $0.91(0.77-1.09)$ \\
\hline+ Lifestyle & $\mathrm{PHI}$ vs SHI & $0.90(0.66-1.22)$ & $0.88(0.69-1.13)$ & $0.86(0.70-1.05)$ & $0.91(0.76-1.09)$ & $0.92(0.77-1.09)$ \\
\hline + Clinical & $\mathrm{PHI}$ vs SHI & $0.90(0.66-1.23)$ & $0.89(0.69-1.14)$ & $0.87(0.70-1.06)$ & $0.93(0.78-1.11)$ & $0.94(0.79-1.11)$ \\
\hline+ Tumor-related & $\mathrm{PHI}$ vs SHI & $0.94(0.69-1.28)$ & $0.92(0.71-1.18)$ & $0.89(0.72-1.10)$ & $0.96(0.80-1.15)$ & $0.97(0.81-1.16)$ \\
\hline+ Treatment & $\mathrm{PHI}$ vs SHI & $0.99(0.72-1.35)$ & $0.91(0.71-1.18)$ & $0.88(0.71-1.09)$ & $0.94(0.78-1.13)$ & $0.95(0.79-1.13)$ \\
\hline \multicolumn{7}{|l|}{ Stages I-II } \\
\hline Crude & $\mathrm{PHI}$ vs SHI & $0.77(0.39-1.54)$ & $0.78(0.46-1.30)$ & $0.62(0.40-0.95)$ & $0.74(0.55-1.01)$ & $0.77(0.58-1.03)$ \\
\hline Demographic & $\mathrm{PHI}$ vs SHI & $0.83(0.41-1.66)$ & $0.84(0.50-1.41)$ & $0.67(0.44-1.03)$ & $0.77(0.57-1.04)$ & $0.79(0.59-1.06)$ \\
\hline + Social & PHI vs SHI & $0.92(0.45-1.88)$ & $0.91(0.54-1.54)$ & $0.70(0.45-1.07)$ & $0.82(0.60-1.11)$ & $0.84(0.63-1.13)$ \\
\hline + Lifestyle & $\mathrm{PHI}$ vs SHI & $0.91(1.44-1.84)$ & $0.90(0.53-1.53)$ & $0.69(0.45-1.06)$ & $0.81(0.59-1.10)$ & $0.83(0.62-1.12)$ \\
\hline + Clinical & $\mathrm{PHI}$ vs SHI & $1.01(0.50-2.06)$ & $0.96(0.56-1.62)$ & $0.73(0.47-1.13)$ & $0.87(0.64-1.19)$ & $0.91(0.68-1.23)$ \\
\hline+ Tumor-related & $\mathrm{PHI}$ vs SHI & $1.05(0.52-2.14)$ & $0.99(0.58-1.68)$ & $0.74(0.48-1.14)$ & $0.89(0.65-1.21)$ & $0.92(0.69-1.24)$ \\
\hline+ Treatment & $\mathrm{PHI}$ vs SHI & $1.03(0.51-2.10)$ & $0.97(0.57-1.65)$ & $0.74(0.48-1.14)$ & $0.89(0.65-1.21)$ & $0.92(0.69-1.24)$ \\
\hline \multicolumn{7}{|l|}{ Stage III } \\
\hline Crude & $\mathrm{PHI}$ vs SHI & $0.75(0.43-1.31)$ & $0.75(0.49-1.14)$ & $0.74(0.52-1.03)$ & $0.74(0.55-0.99)$ & $0.74(0.55-0.99)$ \\
\hline Demographic & $\mathrm{PHI}$ vs SHI & $0.86(0.49-1.51)$ & $0.84(0.55-1.29)$ & $0.84(0.60-1.19)$ & $0.85(0.63-1.15)$ & $0.86(0.64-1.15)$ \\
\hline+ Social & $\mathrm{PHI}$ vs SHI & $0.99(0.55-1.80)$ & $0.83(0.53-1.30)$ & $0.89(0.62-1.28)$ & $0.95(0.69-1.31)$ & $0.94(0.69-1.29)$ \\
\hline+ Lifestyle & $\mathrm{PHI}$ vs SHI & $1.03(0.57-1.87)$ & $0.83(0.53-1.31)$ & $0.90(0.62-1.29)$ & $0.96(0.70-1.32)$ & $0.95(0.69-1.30)$ \\
\hline + Clinical & $\mathrm{PHI}$ vs SHI & $1.09(0.60-1.98)$ & $0.86(0.55-1.36)$ & $0.92(0.64-1.33)$ & $0.98(0.70-1.35)$ & $0.96(0.70-1.33)$ \\
\hline+ Tumor-elated & $\mathrm{PHI}$ vs SHI & $1.11(0.60-2.03)$ & 0.87 (0.55-1.37) & $0.92(0.63-1.33)$ & $0.97(0.70-1.35)$ & $0.96(0.70-1.33)$ \\
\hline+ Treatment & $\mathrm{PHI}$ vs SHI & $1.04(0.57-1.92)$ & $0.82(0.52-1.30)$ & $0.88(0.61-1.27)$ & $0.94(0.67-1.30)$ & $0.93(0.67-1.28)$ \\
\hline \multicolumn{7}{|l|}{ Stage IV } \\
\hline Crude & $\mathrm{PHI}$ vs SHI & $0.79(0.53-1.20)$ & $0.78(0.55-1.11)$ & $0.83(0.61-1.13)$ & $0.87(0.65-1.17)$ & $0.86(0.64-1.16)$ \\
\hline Demographic & $\mathrm{PHI}$ vs SHI & $0.88(0.58-1.33)$ & $0.85(0.60-1.22)$ & $0.91(0.66-1.24)$ & $0.94(0.70-1.27)$ & $0.95(0.70-1.28)$ \\
\hline+ Social & $\mathrm{PHI}$ vs SHI & $0.95(0.62-1.45)$ & $0.93(0.65-1.35)$ & $0.97(0.70-1.34)$ & $0.99(0.73-1.36)$ & $1.01(0.74-1.38)$ \\
\hline+ Lifestyle & $\mathrm{PHI}$ vs SHI & $0.95(0.61-1.45)$ & $0.93(0.64-1.35)$ & $0.97(0.70-1.34)$ & $1.00(0.73-1.37)$ & $1.01(0.74-1.38)$ \\
\hline + Clinical & $\mathrm{PHI}$ vs SHI & $0.92(0.60-1.42)$ & $0.90(0.62-1.31)$ & $0.94(0.68-1.30)$ & $0.97(0.71-1.33)$ & $0.98(0.72-1.35)$ \\
\hline+ Tumor-related & $\mathrm{PHI}$ vs SHI & $0.95(0.62-1.47)$ & $0.93(0.64-1.35)$ & $0.97(0.70-1.34)$ & $1.00(0.73-1.37)$ & $1.01(0.74-1.39)$ \\
\hline+ Treatment & $\mathrm{PHI}$ vs SHI & $1.05(0.67-1.63)$ & $0.94(0.64-1.38)$ & $0.97(0.69-1.35)$ & $0.97(0.70-1.35)$ & $0.98(0.70-1.35)$ \\
\hline
\end{tabular}

Bold indicates statistically significant results.

The level of adjustment was gradually extended: Demographic factors: sex and age at diagnosis; Social factors: years of schooling and living with a partner; Lifestyle factors: lifestyle score; Clinical factors: Charlson comorbidity score, regular use of statins, and regular use of nonsteroidal anti-inflammatory drugs; Tumor-related factors: year of diagnosis, cancer stage, and cancer site; Treatment-related factors: chemotherapy, radiotherapy, and targeted therapy.

Abbreviations: $\mathrm{HR}$, hazard ratio; $\mathrm{PHI}$, private health insurance; $\mathrm{SHI}$, statutory health insurance. 


\section{eTable 4. Association of Insurance Type With CRC-Specific Survival}

\begin{tabular}{|c|c|c|c|c|c|c|}
\hline Group & $\begin{array}{c}\text { Insurance } \\
\text { Type }\end{array}$ & $\begin{array}{l}\text { At } 2 \text { Years } \\
\text { HR }(95 \% \mathrm{Cl})\end{array}$ & $\begin{array}{c}\text { At } 3 \text { Years } \\
\text { HR }(95 \% \mathrm{Cl})\end{array}$ & $\begin{array}{l}\text { At } 5 \text { Years } \\
\text { HR }(95 \% \mathrm{Cl})\end{array}$ & $\begin{array}{l}\text { At } 10 \text { Years } \\
\text { HR }(95 \% \mathrm{Cl})\end{array}$ & $\begin{array}{c}\text { All Years } \\
\text { HR }(95 \% \mathrm{Cl})\end{array}$ \\
\hline \multicolumn{7}{|l|}{ All stages } \\
\hline Crude & $\mathrm{PHI}$ vs $\mathrm{SHI}$ & $0.76(0.54-1.07)$ & $0.79(0.60-1.05)$ & $0.84(0.66-1.06)$ & $0.91(0.74-1.13)$ & $0.92(0.75-1.14)$ \\
\hline Demographic & $\mathrm{PHI}$ vs $\mathrm{SHI}$ & $0.81(0.57-1.14)$ & $0.83(0.62-1.09)$ & $0.87(0.69-1.10)$ & $0.93(0.76-1.16)$ & $0.95(0.77-1.17)$ \\
\hline+ Social & $\mathrm{PHI}$ vs $\mathrm{SHI}$ & $0.83(0.58-1.19)$ & 0.85 (0.67-1.09) & 0.85 (0.67-1.09) & $0.93(0.75-1.16)$ & $0.94(0.75-1.16)$ \\
\hline + Lifestyle & $\mathrm{PHI}$ vs $\mathrm{SHI}$ & $0.83(0.58-1.19)$ & $0.85(0.67-1.09)$ & $0.85(0.67-1.09)$ & $0.93(0.75-1.16)$ & $0.94(0.75-1.16)$ \\
\hline + Clinical & $\mathrm{PHI}$ vs $\mathrm{SHI}$ & $0.82(0.57-1.18)$ & $0.85(0.66-1.08)$ & $0.85(0.67-1.08)$ & $0.93(0.75-1.16)$ & $0.94(0.75-1.16)$ \\
\hline+ Tumor-related & $\mathrm{PHI}$ vs $\mathrm{SHI}$ & $0.89(0.62-1.27)$ & $0.88(0.89-1.13)$ & $0.87(0.68-1.12)$ & $0.96(0.77-1.20)$ & $0.97(0.77-1.21)$ \\
\hline+ Treatment & $\mathrm{PHI}$ vs $\mathrm{SHI}$ & $0.93(0.65-1.35)$ & $0.83(0.62-1.12)$ & $0.86(0.67-1.11)$ & $0.94(0.75-1.18)$ & $0.94(0.75-1.18)$ \\
\hline \multicolumn{7}{|l|}{ Stages I-II } \\
\hline Crude & $\mathrm{PHI}$ vs $\mathrm{SHI}$ & a & $0.38(0.12-1.22)$ & $0.50(0.22-1.14)$ & $0.77(0.44-1.36)$ & $0.85(0.50-1.46)$ \\
\hline Demographic & $\mathrm{PHI}$ vs $\mathrm{SHI}$ & a & $0.43(0.13-1.37)$ & $0.56(0.24-1.28)$ & $0.82(0.46-1.45)$ & $0.90(0.52-1.55)$ \\
\hline+ Social & $\mathrm{PHI}$ vs $\mathrm{SHI}$ & a & $0.47(0.14-1.52)$ & $0.56(0.24-1.30)$ & $0.83(0.46-1.49)$ & $0.91(0.52-1.59)$ \\
\hline + Lifestyle & $\mathrm{PHI}$ vs $\mathrm{SHI}$ & a & $0.46(0.14-1.50)$ & $0.56(0.24-1.29)$ & $0.83(0.46-1.48)$ & $0.90(0.52-1.58)$ \\
\hline + Clinical & $\mathrm{PHI}$ vs SHI & a & $0.48(0.15-1.55)$ & $0.59(0.25-1.36)$ & $0.88(0.49-1.58)$ & $0.96(0.55-1.67)$ \\
\hline+ Tumor-related & $\mathrm{PHI}$ vs SHI & a & $0.49(0.15-1.60)$ & $0.61(0.26-1.40)$ & $0.89(0.50-1.60)$ & $0.97(0.56-1.70)$ \\
\hline+ Treatment & $\mathrm{PHI}$ vs $\mathrm{SHI}$ & a & $0.48(0.15-1.55)$ & $0.59(0.26-1.37)$ & $0.89(0.49-1.59)$ & $0.97(0.56-1.69)$ \\
\hline \multicolumn{7}{|l|}{ Stage III } \\
\hline Crude & $\mathrm{PHI}$ vs $\mathrm{SHI}$ & $0.86(0.46-1.60)$ & $0.80(0.49-1.30)$ & $0.80(0.54-1.19)$ & $0.87(0.61-1.23)$ & $0.87(0.61-1.23)$ \\
\hline Demographic & $\mathrm{PHI}$ vs $\mathrm{SHI}$ & $0.97(0.52-1.81)$ & $0.87(0.54-1.42)$ & $0.88(0.59-1.31)$ & $0.94(0.66-1.34)$ & $0.94(0.66-1.34)$ \\
\hline+ Social & $\mathrm{PHI}$ vs $\mathrm{SHI}$ & $1.01(0.52-1.97)$ & $0.74(0.44-1.24)$ & $0.80(0.52-1.22)$ & $0.91(0.62-1.32)$ & $0.88(0.60-1.28)$ \\
\hline+ Lifestyle & $\mathrm{PHI}$ vs $\mathrm{SHI}$ & $1.03(0.53-2.02)$ & $0.74(0.44-1.25)$ & $0.79(0.52-1.22)$ & $0.91(0.62-1.32)$ & $0.88(0.60-1.28)$ \\
\hline+ Clinical & $\mathrm{PHI}$ vs $\mathrm{SHI}$ & $1.05(0.53-2.06)$ & $0.76(0.45-1.28)$ & $0.80(0.52-1.23)$ & $0.92(0.63-1.34)$ & $0.89(0.61-1.30)$ \\
\hline+ Tumor-related & $\mathrm{PHI}$ vs $\mathrm{SHI}$ & $1.05(0.53-2.08)$ & $0.75(0.44-1.27)$ & $0.80(0.52-1.23)$ & $0.91(0.62-1.33)$ & $0.89(0.61-1.29)$ \\
\hline+ Treatment & $\mathrm{PHI}$ vs $\mathrm{SHI}$ & $1.02(0.52-2.02)$ & $0.73(0.43-1.23)$ & $0.78(0.51-1.20)$ & $0.89(0.61-1.31)$ & $0.87(0.59-1.27)$ \\
\hline \multicolumn{7}{|l|}{ Stage IV } \\
\hline Crude & $\mathrm{PHI}$ vs $\mathrm{SHI}$ & $0.79(0.52-1.21)$ & $0.79(0.55-1.14)$ & $0.82(0.60-1.12)$ & $0.89(0.66-1.20)$ & $0.89(0.66-1.20)$ \\
\hline Demographic & $\mathrm{PHI}$ vs $\mathrm{SHI}$ & $0.88(0.58-1.35)$ & $0.87(0.60-1.25)$ & $0.92(0.67-1.26)$ & $0.96(0.70-1.30)$ & $0.96(0.70-1.30)$ \\
\hline+ Social & $\mathrm{PHI}$ vs $\mathrm{SHI}$ & $0.96(0.62-1.48)$ & $0.96(0.66-1.40)$ & $0.98(0.70-1.37)$ & $1.01(0.74-1.40)$ & $1.01(0.74-1.40)$ \\
\hline+ Lifestyle & $\mathrm{PHI}$ vs $\mathrm{SHI}$ & $0.96(0.62-1.49)$ & $0.96(0.66-1.39)$ & $0.98(0.71-1.37)$ & $1.02(0.74-1.40)$ & $1.02(0.74-1.40)$ \\
\hline + Clinical & $\mathrm{PHI}$ vs $\mathrm{SHI}$ & $0.94(0.60-1.46)$ & $0.93(0.64-1.36)$ & $0.96(0.69-1.34)$ & $1.00(0.72-1.38)$ & $1.00(0.72-1.38)$ \\
\hline+ Tumor-related & $\mathrm{PHI}$ vs $\mathrm{SHI}$ & $0.97(0.62-1.51)$ & $0.96(0.66-1.40)$ & $0.99(0.71-1.39)$ & $1.03(0.74-1.42)$ & $1.03(0.74-1.42)$ \\
\hline+ Treatment & $\mathrm{PHI}$ vs SHI & $1.06(0.68-1.67)$ & $0.97(0.66-1.44)$ & $0.99(0.70-1.39)$ & $1.00(0.72-1.40)$ & $1.00(0.72-1.40)$ \\
\hline
\end{tabular}

The level of adjustment was gradually extended: Demographic factors: sex and age at diagnosis; Social factors: years of schooling and living with a partner; Lifestyle factors: lifestyle score; Clinical factors: Charlson comorbidity score, regular use of statins, and regular use of nonsteroidal anti-inflammatory drugs; Tumor-related factors: year of diagnosis, cancer stage, and cancer site; Treatment-related factors: chemotherapy, radiotherapy, and targeted therapy.

Abbreviations: CRC, colorectal cancer; HR, hazard ratio; PHI, private health insurance; SHI, statutory health insurance.

aOutcome was not matured for analysis. 
eTable 5. Association of Insurance Type With Recurrence-Free Survivala

\begin{tabular}{|c|c|c|c|c|c|c|}
\hline Group & $\begin{array}{c}\text { Insurance } \\
\text { Type }\end{array}$ & $\begin{array}{l}\text { At } 2 \text { Years } \\
\text { HR }(95 \% \mathrm{Cl})\end{array}$ & $\begin{array}{c}\text { At } 3 \text { Years } \\
\text { HR }(95 \% \mathrm{Cl})\end{array}$ & $\begin{array}{l}\text { At } 5 \text { Years } \\
\text { HR }(95 \% \mathrm{Cl})\end{array}$ & $\begin{array}{l}\text { At } 10 \text { Years } \\
\text { HR }(95 \% \mathrm{Cl})\end{array}$ & $\begin{array}{c}\text { All Years } \\
\text { HR }(95 \% \mathrm{Cl})\end{array}$ \\
\hline \multicolumn{7}{|l|}{ Stages I-III } \\
\hline Demographic & $\mathrm{PHI}$ vs $\mathrm{SHI}$ & $0.72(0.39-1.33)$ & $0.80(0.52-1.24)$ & $0.85(0.61-1.18)$ & $0.95(0.73-1.23)$ & $0.96(0.75-1.24)$ \\
\hline+ Social & $\mathrm{PHI}$ vs SHI & $0.81(0.43-1.53)$ & $0.78(0.50-1.23)$ & $0.82(0.59-1.15)$ & $0.92(0.70-1.21)$ & $0.91(0.70-1.10)$ \\
\hline+ Tumor-related & $\mathrm{PHI}$ vs SHI & $0.78(0.41-1.49)$ & $0.72(0.46-1.14)$ & $0.76(0.54-1.07)$ & $0.87(0.66-1.15)$ & $0.88(0.68-1.14)$ \\
\hline + Treatment & $\mathrm{PHI}$ vs $\mathrm{SHI}$ & $0.78(0.41-1.48)$ & $0.71(0.45-1.12)$ & $0.76(0.54-1.07)$ & $0.87(0.66-1.15)$ & $0.87(0.67-1.14)$ \\
\hline \multicolumn{7}{|l|}{ Stages I-II } \\
\hline Crude & $\mathrm{PHI}$ vs SHI & b & $0.38(0.12-1.20)$ & $0.69(0.36-1.31)$ & $0.77(0.48-1.24)$ & $0.75(0.48-1.18)$ \\
\hline + Clinical & $\mathrm{PHI}$ vs SHI & b & $0.48(0.15-1.56)$ & $0.74(0.38-1.43)$ & $0.80(0.49-1.30)$ & $0.73(0.46-1.16)$ \\
\hline+ Tumor-related & PHI vs SHI & b & $0.50(0.15-1.62)$ & $0.75(0.39-1.45)$ & $0.80(0.49-1.31)$ & $0.74(0.47-1.17)$ \\
\hline + Treatment & $\mathrm{PHI}$ vs SHI & b & $0.49(0.15-1.59)$ & $0.74(0.38-1.44)$ & $0.80(0.49-1.31)$ & $0.74(0.47-1.18)$ \\
\hline \multicolumn{7}{|l|}{ Stage III } \\
\hline Crude & $\mathrm{PHI}$ vs SHI & $0.83(0.45-1.55)$ & $0.82(0.51-1.31)$ & $0.78(0.54-1.14)$ & $0.93(0.68-1.28)$ & $0.99(0.73-1.34)$ \\
\hline Demographic & $\mathrm{PHI}$ vs SHI & $0.94(0.50-1.75)$ & $0.89(0.55-1.43)$ & $0.85(0.58-1.25)$ & $0.99(0.72-1.35)$ & $1.05(0.77-1.42)$ \\
\hline + Social & PHI vs SHI & $0.99(0.51-1.92)$ & $0.77(0.46-1.27)$ & $0.80(0.53-1.19)$ & $0.92(0.66-1.29)$ & $0.96(0.69-1.32)$ \\
\hline + Lifestyle & $\mathrm{PHI}$ vs SHI & $1.01(0.52-1.96)$ & $0.77(0.46-1.28)$ & $0.79(0.53-1.19)$ & $0.93(0.66-1.30)$ & $0.96(0.69-1.33)$ \\
\hline + Clinical & $\mathrm{PHI}$ vs SHI & $1.02(0.52-2.00)$ & $0.78(0.47-1.29)$ & $0.80(0.53-1.20)$ & $0.94(0.67-1.31)$ & $0.97(0.70-1.35)$ \\
\hline
\end{tabular}

The level of adjustment was gradually extended: Demographic factors: sex and age at diagnosis; Social factors: years of schooling and living with a partner; Lifestyle factors: lifestyle score; Clinical factors: Charlson comorbidity score, regular use of statins, and regular use of nonsteroidal anti-inflammatory drugs; Tumor-related factors: year of diagnosis, cancer stage, and cancer site; Treatment-related factors: chemotherapy, radiotherapy, and targeted therapy. Abbreviations: HR, hazard ratio; PHI, private health insurance; $\mathrm{SHI}$, statutory health insurance.

a Analysis of recurrence-free survival was restricted to stage I-III patients.

bOutcome was not matured for analysis. 
eTable 6. Comparison of Patient Characteristics Between Included and Excluded Participants

\begin{tabular}{|c|c|c|c|}
\hline \multirow[b]{2}{*}{ Factor } & \multicolumn{2}{|c|}{ DACHS } & \multirow[b]{2}{*}{$P$ Value } \\
\hline & Included & Excluded & \\
\hline Patients, N & 3,977 & 939 & \\
\hline \multicolumn{4}{|l|}{ Demographic } \\
\hline Sex & & & .0332 \\
\hline Female & $1,603(40.3)$ & $343(36.5)$ & \\
\hline Male & $2,374(59.7)$ & $596(63.5)$ & \\
\hline Age at diagnosis, $y$ & & & $<.0001$ \\
\hline $30-59$ & $776(19.5)$ & $275(29.2)$ & \\
\hline $60-69$ & $1,150(28.9)$ & $317(33.8)$ & \\
\hline $70-79$ & $1,368(34.4)$ & $261(27.8)$ & \\
\hline$\geq 80$ & $683(17.2)$ & $86(9.2)$ & \\
\hline Median (IQR) & $70(62-77)$ & $66(57-73)$ & \\
\hline \multicolumn{4}{|l|}{ Social } \\
\hline Years of school education & & & $<.0001$ \\
\hline$<9 y$ & $2,695(67.9)$ & $525(56.0)$ & \\
\hline $9-10 y$ & $684(17.2)$ & $170(18.1)$ & \\
\hline$>10 y$ & $590(14.9)$ & $242(25.8)$ & \\
\hline Living with a partner & & & .0005 \\
\hline No & $1,054(26.5)$ & $197(21.0)$ & \\
\hline Yes & $2,918(73.5)$ & $741(79.0)$ & \\
\hline
\end{tabular}

Lifestyle

Lifestyle score

.2034

\begin{tabular}{lll}
\hline Meet 0-2 recommendations & $1,159(30.7)$ & $302(33.3)$ \\
\hline Meet 3 recommendations & $1,362(36.1)$ & $302(33.3)$ \\
\hline Meet 4-5 recommendations & $1,255(33.2)$ & $304(33.5)$
\end{tabular}

Clinical

Charlson comorbidity score ${ }^{a}$

None (0)

$192(55.1)$

$568(60.5)$

Mild (1)

859 (21.6)

$191(20.3)$

Moderate/Severe $(\geq 2)$

$926(23.3)$

$180(19.2)$

Tumor-related

Year of diagnosis

\begin{tabular}{lll}
\hline $2003-2006$ & $1,314(33.0)$ & $359(38.2)$ \\
\hline $2007-2010$ & $1,342(33.7)$ & $256(27.3)$ \\
\hline $2011-2014$ & $1,321(33.2)$ & $324(34.5)$
\end{tabular}

Cancer stage

$873(22.8) \quad 154(17.7)$

II $\quad 1,188(30.1) \quad 241(27.7)$

III $\quad 1,221(31.8) \quad 311(35.8)$

IV $556(14.5) \quad 163(18.8)$ (continued)

\begin{tabular}{|c|c|c|c|}
\hline \multirow[b]{2}{*}{ Factor } & \multicolumn{2}{|c|}{ DACHS } & \multirow[b]{2}{*}{$P$ Value } \\
\hline & Included & Excluded & \\
\hline \multicolumn{4}{|l|}{ Tumor-related (cont.) } \\
\hline Cancer site & & & $<.0001$ \\
\hline Colon & $1,473(37.0)$ & $517(55.1)$ & \\
\hline Rectosigmoid/Rectum & $2,504(63.0)$ & $422(44.9)$ & \\
\hline \multicolumn{4}{|l|}{ Treatment } \\
\hline Type of surgery ${ }^{b}$ & & & $<.0001$ \\
\hline None & $70(1.8)$ & $17(1.8)$ & \\
\hline Open & $3,303(83.1)$ & $831(88.8)$ & \\
\hline Laparoscopic & $598(15.1)$ & $88(9.4)$ & \\
\hline Radiotherapy ${ }^{c}$ & & & $<.0001$ \\
\hline No & $3,350(84.4)$ & $644(69.6)$ & \\
\hline Yes & $620(15.6)$ & $282(30.5)$ & \\
\hline Chemotherapy ${ }^{c}$ & & & .0034 \\
\hline No & $2,205(55.5)$ & $465(50.2)$ & \\
\hline Yes & $1,765(44.5)$ & $461(49.8)$ & \\
\hline Targeted therapy ${ }^{c}$ & & & .0001 \\
\hline No & $3,737(94.0)$ & $840(90.5)$ & \\
\hline Yes & $237(6.0)$ & $88(9.5)$ & \\
\hline
\end{tabular}

Missing data ( $\mathrm{n}$ [\%]; included vs excluded): years of school education (8 [0.2] vs $2[0.2])$, living with a partner (5 [0.1] vs 1 [0.1]), lifestyle score (201 [5.1] vs $31[3.3])$, tumor stage (139 [3.5] vs $70[7.5])$, surgery (6 [0.2] vs $3[0.3])$, radiotherapy $(7[0.2]$ vs $13[1.4])$, chemotherapy $(7[0.2]$ vs $13[1.4])$, and immunotherapy (3 [0.1] vs 11 [1.2]).

Abbreviations: DACHS, Darmkrebs: Chancen der Verhütung durch Screening study; IQR, interquartile range.

aCharlson comorbidity score was calculated based on comorbidities at diagnosis.

bLaparoscopic surgeries include laparoscopic surgeries that were converted to open surgeries.

cFirst-line adjuvant or neoadjuvant treatment. 


\section{8 - Jansen et al}

A

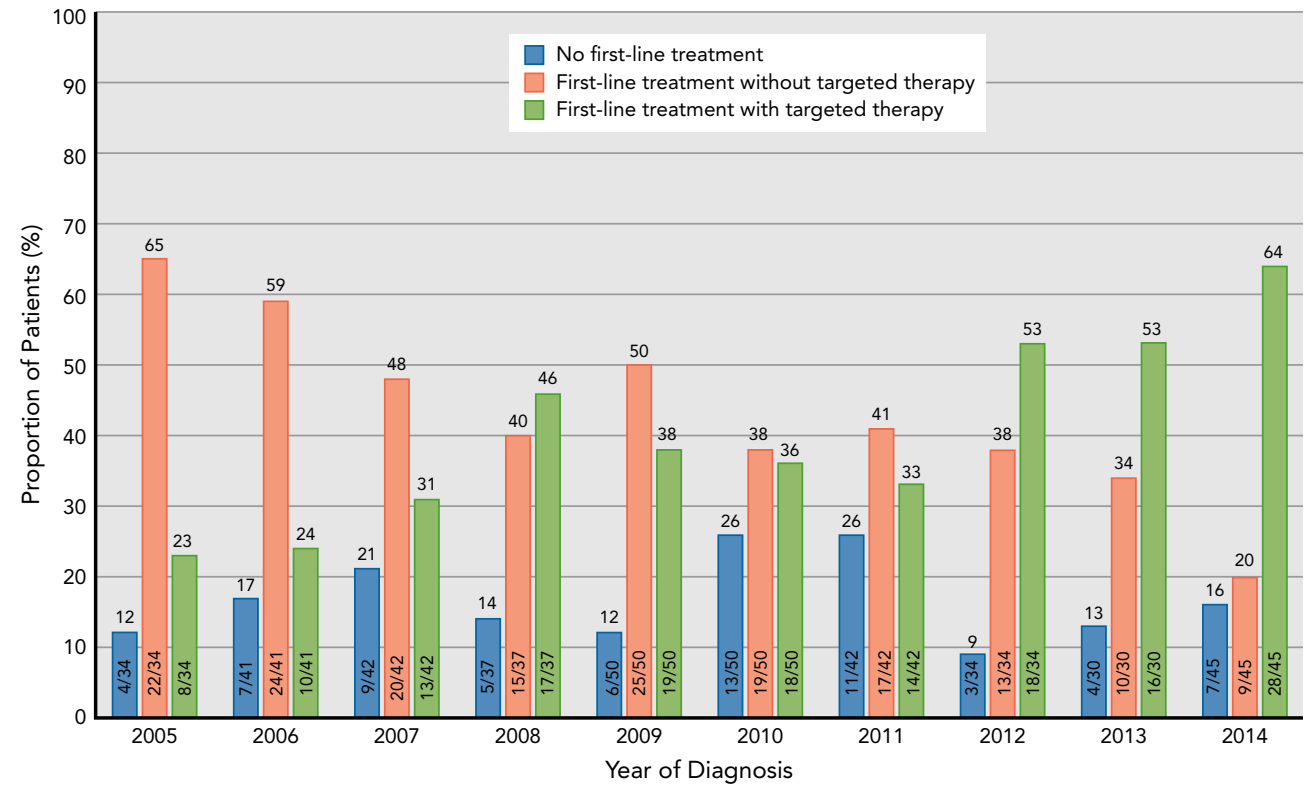

B

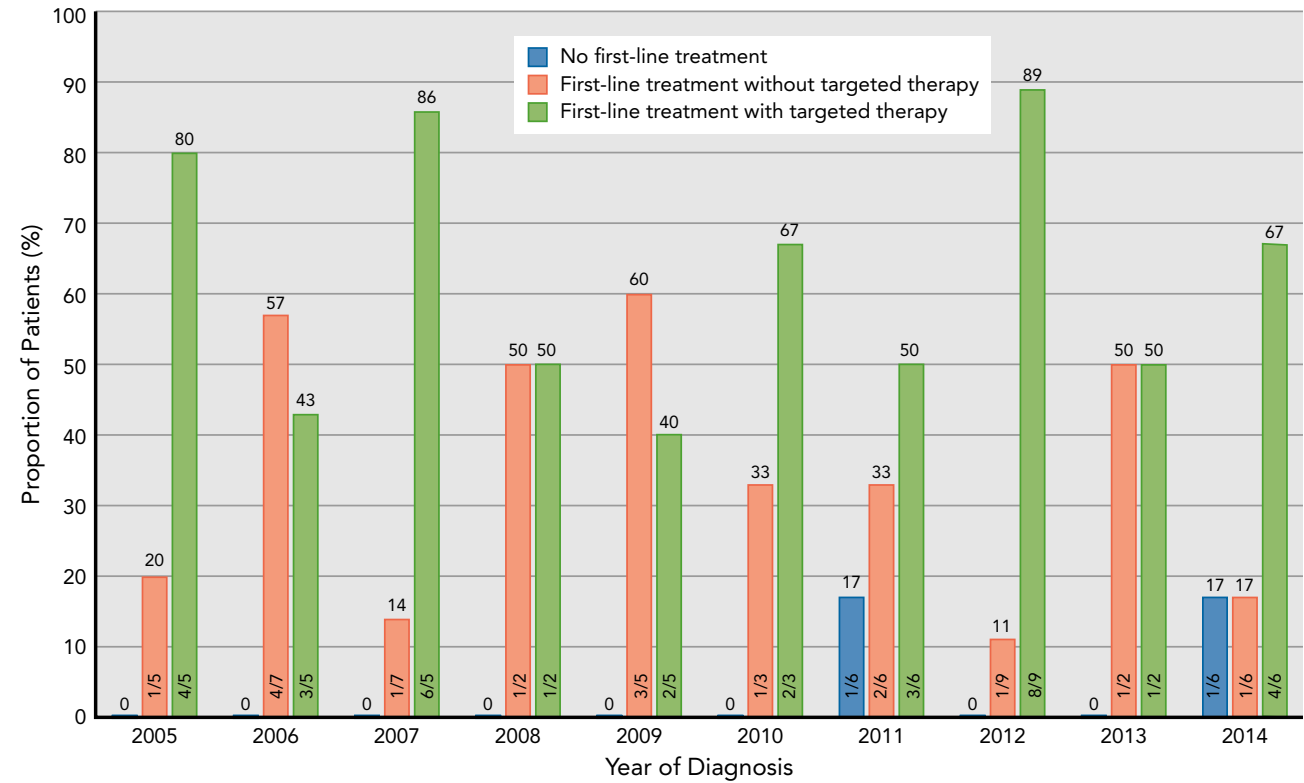

eFigure 1. Proportion of patients with stage IV colorectal cancer with (A) public and (B) private health insurance who received first-line chemotherapy with or without targeted therapy by year of diagnosis. Analysis was restricted to years of diagnosis $\geq 2005$ because no patient received targeted therapy before 2005 (results are the average over all datasets from multiple imputation). 